\title{
Mapping Ground Instability in Areas of Geotechnical Infrastructure Using Satellite InSAR and Small UAV Surveying: A Case Study in Northern Ireland
}

\author{
Francesca Cigna ${ }^{1, *}$ (D) , Vanessa J. Banks ${ }^{1,+}+\mathbb{D}$, Alexander W. Donald ${ }^{1,2,+}$, Shane Donohue ${ }^{3,+}$, \\ Conor Graham ${ }^{4,+}$, David Hughes ${ }^{3,+}$, Jennifer M. McKinley ${ }^{4,+}$ and Kieran Parker ${ }^{1,2,+}$ \\ 1 British Geological Survey, Natural Environment Research Council, Nicker Hill, Keyworth NG12 5GG, UK; \\ vbanks@bgs.ac.uk (V.J.B.); awdo@bgs.ac.uk (A.W.D.); kiepar@bgs.ac.uk (K.P.) \\ 2 Geological Survey of Northern Ireland, Dundonald House, Upper Newtownards Road, Belfast BT4 3SB, UK \\ 3 Civil Engineering, School of Natural and Built Environment, Queen's University Belfast, Stranmillis Road, \\ Belfast BT9 5AG, UK; s.donohue@qub.ac.uk (S.D.); d.hughes@qub.ac.uk (D.H.) \\ 4 Centre for GIS and Geomatics, School of Natural and Built Environment, Queen's University Belfast, \\ Elmwood Ave., Belfast BT7 1NN, UK; conor.graham@qub.ac.uk (C.G.); j.mckinley@qub.ac.uk (J.M.M.) \\ * Correspondence: francesca.cigna@gmail.com \\ + These authors are listed in alphabetical order.
}

Received: 7 April 2017; Accepted: 29 June 2017; Published: 6 July 2017

\begin{abstract}
Satellite Interferometric Synthetic Aperture Radar (InSAR), geological data and Small Unmanned Aerial Vehicle (SUAV) surveying was used to enhance our understanding of ground movement at five areas of interest in Northern Ireland. In total 68 ERS-1/2 images 1992-2000 were processed with the Small Baseline Subset (SBAS) InSAR technique to derive the baseline ground instability scenario of key areas of interest for five stakeholders: TransportNI, Northern Ireland Railways, Department for the Economy, Arup, and Belfast City Council. These stakeholders require monitoring of ground deformation across either their geotechnical infrastructure (i.e., embankments, cuttings, engineered fills and earth retaining structures) or assessment of subsidence risk as a result of abandoned mine workings, using the most efficient, cost-effective methods, with a view to minimising and managing risk to their businesses. The InSAR results provided an overview of the extent and magnitude of ground deformation for a $3000 \mathrm{~km}^{2}$ region, including the key sites of the disused salt mines in Carrickfergus, the Belfast-Bangor railway line, Throne Bend and Ligoniel Park in Belfast, Straidkilly and Garron Point along the Antrim Coast Road, plus other urbanised areas in and around Belfast. Tailored SUAV campaigns with a X8 airframe and generation of very high resolution ortho-photographs and a 3D surface model via the Structure from Motion (SfM) approach at Maiden Mount salt mine collapse in Carrickfergus in 2016 and 2017 also demonstrate the benefits of very high resolution surveying technologies to detect localised deformation and indicators of ground instability.

Keywords: Synthetic Aperture Radar (SAR); Interferometric SAR (InSAR); Small Unmanned Aerial Vehicle (SUAV); Structure from Motion (SfM); ground deformation; slope stability; land subsidence; transport infrastructure; abandoned mines
\end{abstract}

\section{Introduction}

Ground movement is an issue of global concern and one that regularly grabs the attention of the media due to its impact on public safety, property and infrastructure networks, often necessitating expensive remedial action.

In Northern Ireland, ground movement is closely associated with slope instability, most notably on the margin and valley slopes of the Antrim plateau as well as surface subsidence in areas of 
historic mining [1]. While the origin of most of this movement is geologically controlled, human influences may also cause instability through urban development, historic mineral extraction and mining. The extent and form of surface motions can vary dramatically from location to location, with a number of controlling factors.

These movements are traditionally monitored by installing instrumentation around sites that have been causing persistent problems. Traditional monitoring methods are often costly and time-consuming while also limited by resources, enabling only small localised areas to be assessed over the long term. Consequently, there is a clearly an opportunity for accurate assessment of ground motion to benefit land-use planning and development across areas suspected of being susceptible to movement, particularly where this facilitates a better understanding of the instigating factors, and the development of tools that will enable early warning of catastrophic movement events.

Since the beginning of 2016, Queen's University Belfast, the British Geological Survey and the Geological Survey of Northern Ireland have been working on a research study to analyse the benefits of using satellite Interferometric Synthetic Aperture Radar (InSAR) techniques (e.g., [2]) to remotely assess ground stability and motion due to slope instability and mining subsidence in Northern Ireland and to identify, understand and quantify environmental risks to geotechnical infrastructure (i.e., embankments, cuttings, engineered fills and earth retaining structures).

The project is funded by the UK's Natural Environment Research Council under the Environmental Risks to Infrastructure Innovation Programme, and is analysing historical radar data obtained from the European Space Agency (ESA)-operated ERS-1/2 and ENVISAT satellites, in preparation for the exploitation of new Earth explorers (i.e., Copernicus' Sentinel-1). These data are processed with multi-temporal InSAR techniques which have been effectively used in other areas of interest to estimate ground motion rates from space with up to millimetre precision, for instance, to map landslides (e.g., [3-5]) and land subsidence (e.g., [6-8]).

The goal of this paper is to contribute to the discussion on the benefits that InSAR methods can provide for geotechnical infrastructure stakeholders, such as transport (e.g., roads and rails) and mining infrastructure owners. InSAR techniques have the capability to remotely monitor large areas, which would enable a step-change in techniques and data currently used by organisations to analyse risk to their infrastructure network.

To demonstrate this impact, the project team is working with five major stakeholders to examine areas of historical slope instability and subsidence, while also aiding the identification of other risk areas:

- TransportNI: a business unit within the Department for Infrastructure, playing a significant role in facilitating safe and convenient movement of people and goods throughout the province and the safety of road users, through delivery of road maintenance services and management and development of the transport network;

- Northern Ireland Railways: the publicly owned railway operator in Northern Ireland, a subsidiary of Translink;

- Department for the Economy: a devolved Northern Ireland government department in the Northern Ireland Executive, previously known as the Department for Enterprise, Trade and Investment, responsible for a number of policy areas, including economic policy development, energy, health and safety at work, mineral development and tourism;

- Belfast City Council: the local authority with responsibility for part of the city of Belfast;

- Arup: a multinational professional services firm providing engineering, design, planning, project management and consulting services for all aspects of the built environment.

These stakeholders all have a common requirement for ground deformation data either across their geotechnical assets or to assess subsidence risk (e.g., as a result of mine collapse) using the most efficient, cost effective methods, with a view to minimising and managing the geotechnical risk to their network and the general public. 
Through the use of (i) InSAR to derive a regional baseline of ground stability and motion; (ii) ground truthing to provide validation; and (iii) Small Unmanned Aerial Vehicle (SUAV) surveying to derive high-resolution ortho-photography and 3D surface models, this study showcases the potential for these stakeholders to monitor ground deformation remotely from space and with aerial vehicles, in a more cost-effective, efficient, and systematic way.

The paper focuses on the analysis of InSAR in the context of the geological data for the key areas of interest identified by the stakeholders (Figures 1-3), and potentially other areas that exhibit significant ground motion rates, likely induced by consolidation settlement and dewatering.

An InSAR analysis for the period 1992-2000 is carried out to analyse historical radar data to assess the baseline ground motion scenario of the areas of interest, in preparation for the exploitation of more recent data from the ENVISAT (2002-2012) and Sentinel-1 (2014-onwards) missions.

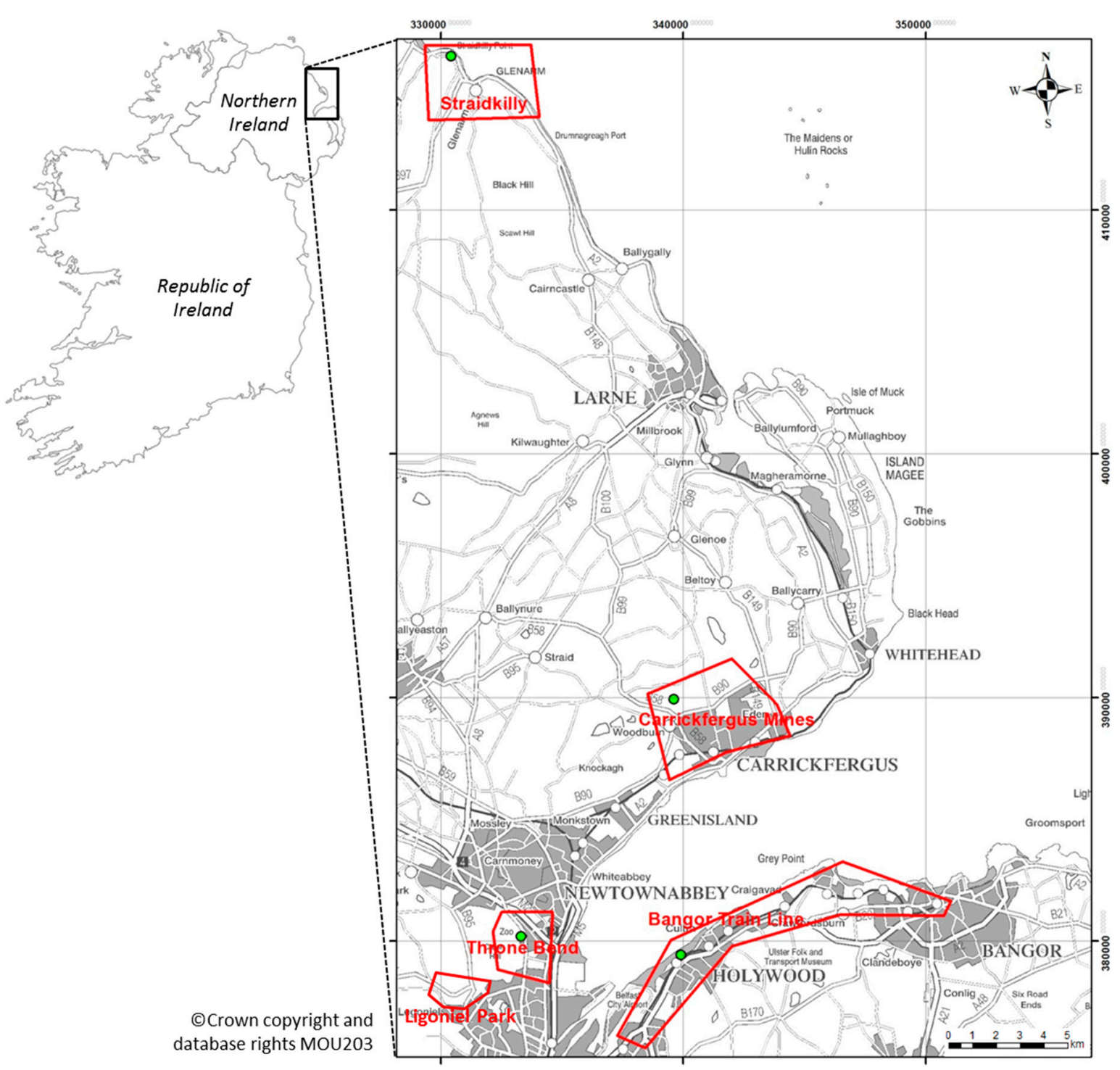

Figure 1. Location of the areas of interest onto topographic map. Reproduced from Land and Property Services data with the permission of the Controller of Her Majesty's Stationery Office, (C) Crown copyright and database rights MOU203.

The InSAR results are first assessed in relation to the distribution and density of identified monitoring targets across the processed area, then observed rates and spatial patterns of annual 
ground motion and example deformation time series are considered for selected targets, enabling any non-linearity to be highlighted.

Brief geological descriptions and tables with a summary of the local geological context and an interpretation of the observed movements are also provided for each of the focus areas.

The results are discussed with respect to embedding these technologies across the stakeholder organisations, and the potential to make a step-change in how stakeholders approach assessment and manage the resilience of their geotechnical infrastructure using network-wide data and, ultimately, reduce network wide monitoring and remediation costs.
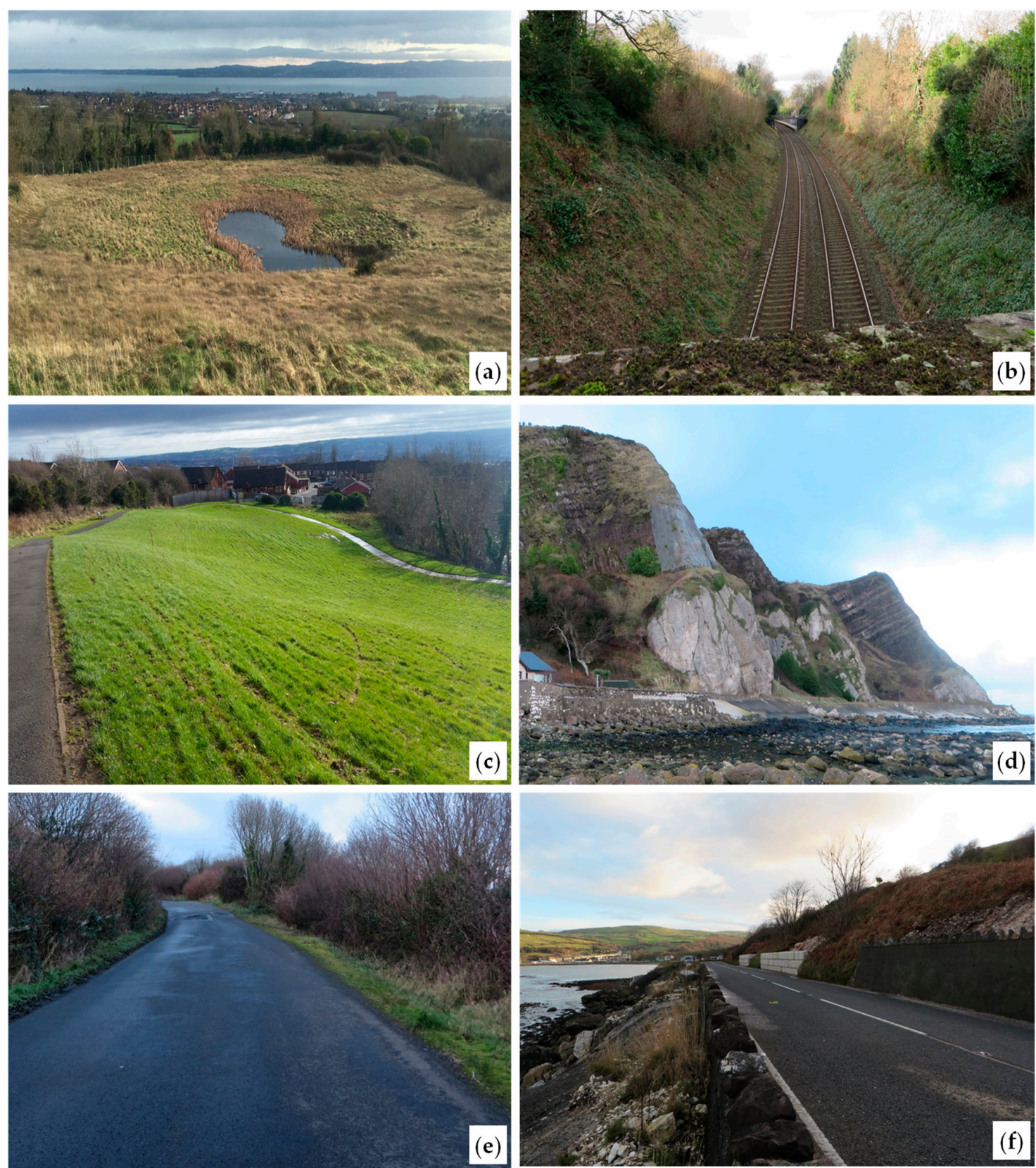

Figure 2. Photographs of the areas of interest taken on 9 February 2016: (a) Maiden Mount salt mine collapse, Carrickfergus; (b) Belfast-Bangor railway line; (c) Ligoniel Park; (d) Garron Point; (e) Straidkilly Road; and (f) stabilisation works along the Antrim Coast Road. 

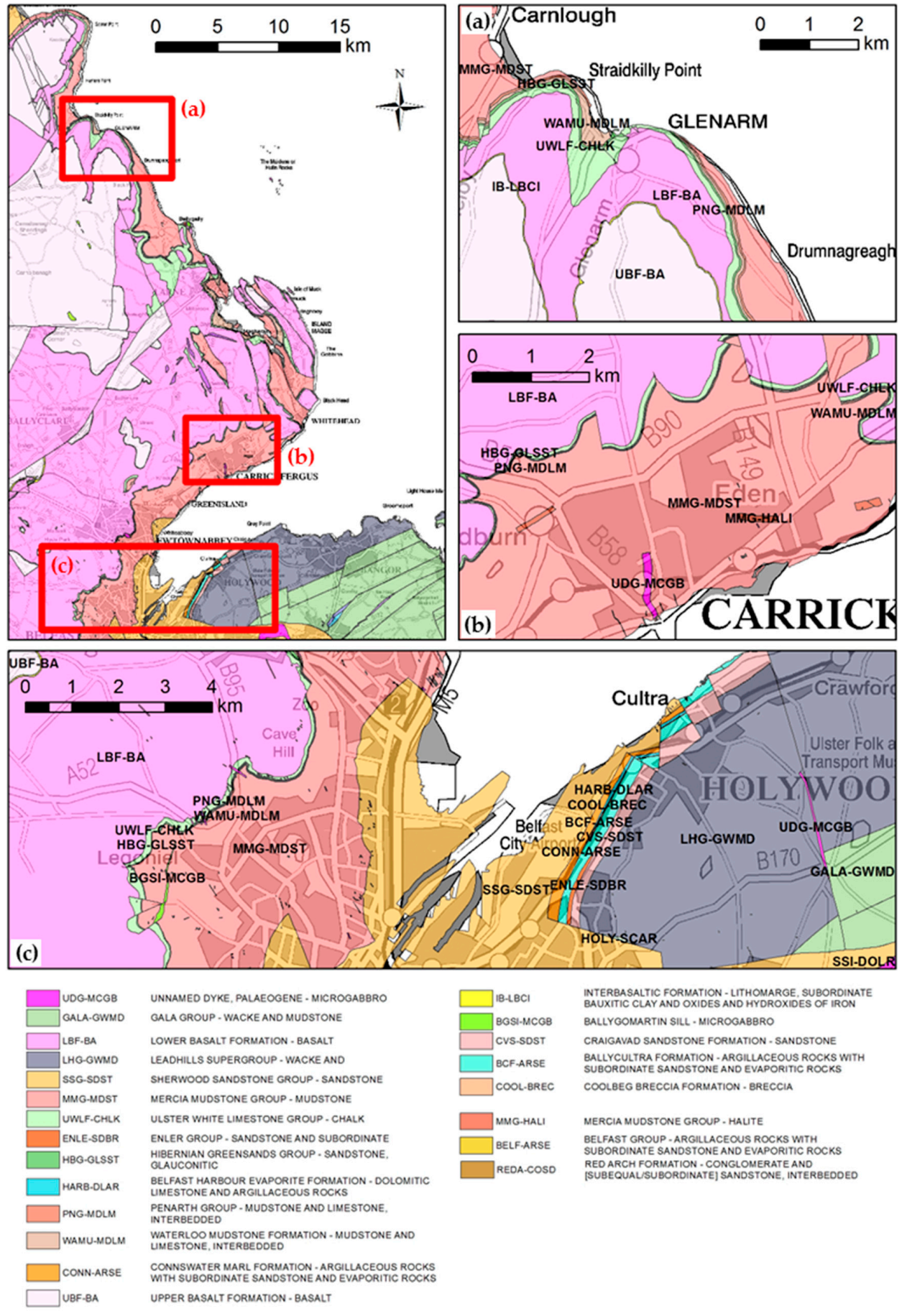

Figure 3. Bedrock geology of the study areas at 1:10,000 scale overlapped onto topography at 1:250,000 scale. (a) Straidkilly; (b) Carrickfergus mines and (c) Bangor Rail Line, Ligoniel Park and Throne Bend. Reproduced from Land and Property Services data with the permission of the Controller of Her Majesty's Stationery Office, (c) Crown copyright and database rights MOU203.

\section{Study Areas}

The regions of interest of this study as identified by the stakeholders focus closely on problematic sites where geotechnical infrastructure is affected by ground instability caused by land subsidence and/or landslide processes. In particular, the key areas of interest are (Figure 1): 
- Carrickfergus: a residential town containing eight abandoned salt mines that display continual subsidence. Over the past two decades a number of crown holes have appeared at various locations as a result of mine collapses (Figure 2a), resulting in permanent closure of two public roads and re-routing of the main gas pipeline in an area of residential and commercial use.

- Belfast-Bangor railway line: this section of railway line is positioned within steep-sided cuttings prone to instability (Figure $2 b$ ), particularly after periods of heavy and prolonged rainfall, which occasionally cause disruption to the line.

- North Belfast: a densely populated, urban location, this area has been subject to shallow translational landslides with evidence of slope and road movement seen at Ligoniel Park (Figure 2c) and Throne Bend on the Antrim Road. At Throne Bend, a large translation slide, which reactivates during extreme rainfall events and affects a residential area, is present.

- Straidkilly and Garron Point, Antrim Coast Road (A2) (Figure 2d-f): positioned at the base of the Antrim Plateau, the A2 is a scenic route used extensively to access the many coastal towns and villages as well as a high number of tourist sites. This section of road cuts through soft Jurassic clays and debris from the slide area has frequently reached the road, increasing the risk to users and also leading to closures of this heavily trafficked strategic road, as well as the Straidkilly Road [9].

\section{Materials and Methods}

\subsection{Satellite Data and InSAR Analysis}

Sixty-eight Synthetic Aperture Radar (SAR) images acquired between 15 April 1992 and 23 December 2000 by ESA's radar satellites ERS-1 and ERS-2 were used to analyse the baseline ground motion for each area of interest. These satellite scenes cover a region of $100 \mathrm{~km}$ by $100 \mathrm{~km}$ (Figure 4a) encompassing over $3000 \mathrm{~km}^{2}$ of land. In addition to the key areas of interest to the project, this area also includes a large portion of the rail and road networks of Northern Ireland, as well as abandoned mines north of Belfast. The entire County Antrim and portions of counties Down, Armagh Tyrone and Derry/Londonderry are covered by the satellite ground footprint.
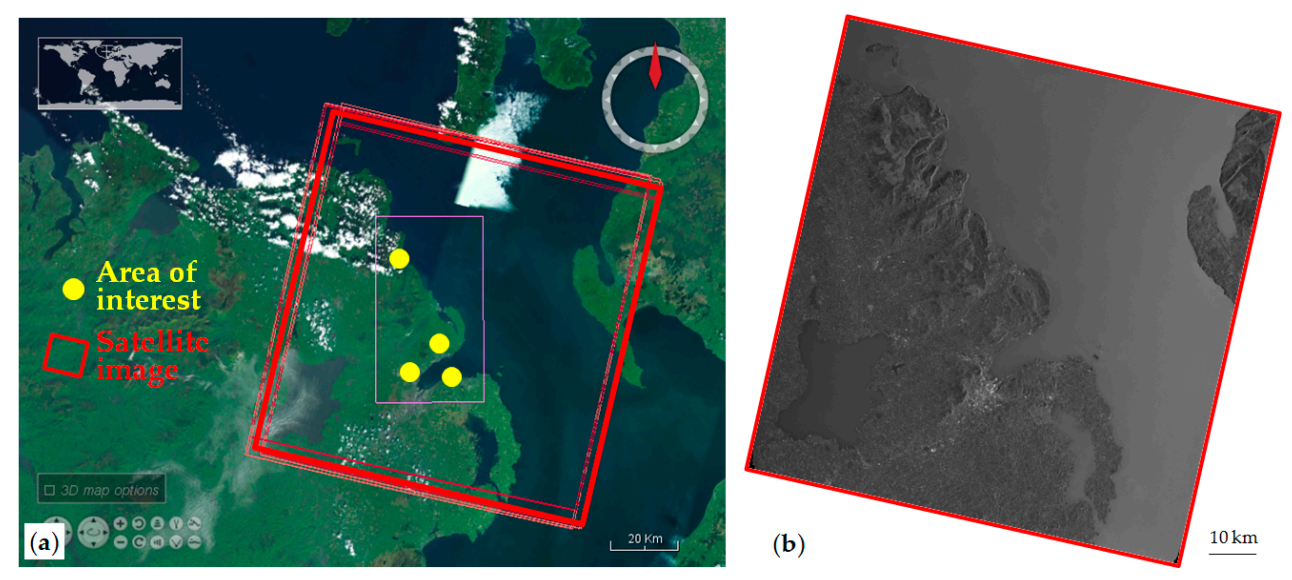

Figure 4. (a) Location of the areas of interest and satellite image footprints, and (b) average Synthetic Aperture Radar (SAR) amplitude of the ERS-1/2 data stack. ERS-1/2 data @ European Space Agency (ESA) 2016.

The ERS-1/2 satellite images are characterised by medium spatial resolution ( $\sim 25 \mathrm{~m}$ ground resolution) with a nominal repeat cycle of 35 days for each satellite ( monthly revisit). A data gap in the satellite data exists between the end of 1993 and early-1995, when ERS-1 was operated by ESA in different orbits and modes. The 68 images were acquired by SAR sensors operating in C-band (5.3 GHz frequency, $5.6 \mathrm{~cm}$ wavelength $\lambda$ ) when the satellites were flying along their descending orbits 
(i.e., approximately from north to south; Figure 5a,b). The Lines-Of-Sight (LOS) employed by both sensors are characterised by look angle $\theta$ of $23^{\circ}$ with respect to the vertical direction, and observe the ground from east to west.

(a)

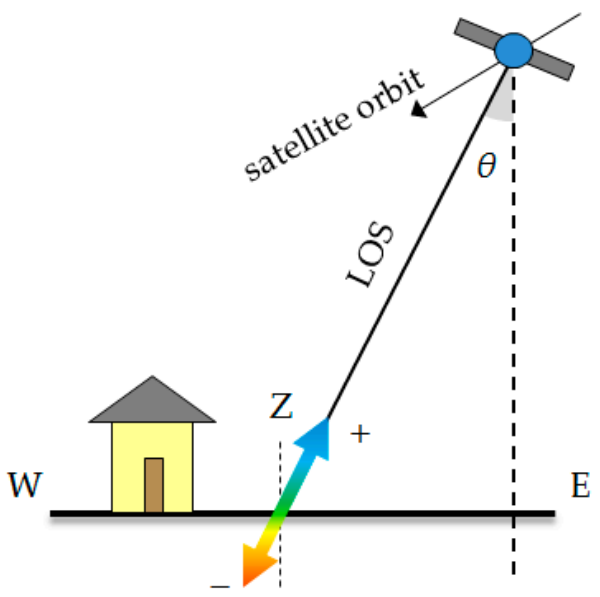

(b)

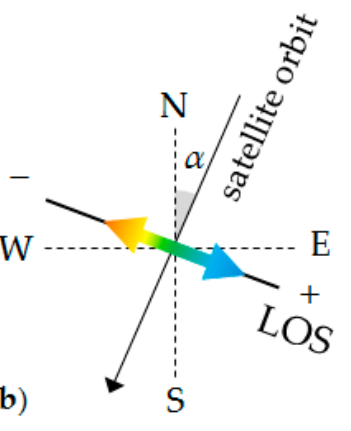

Centre point of the 100 by $100 \mathrm{~m}$ parcel

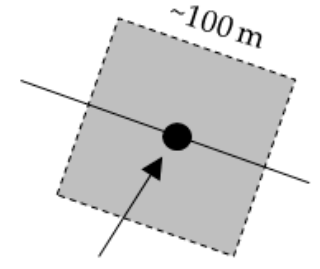

(c)

Figure 5. (a) Vertical and (b) planar view of the satellite Line-Of-Sight (LOS) in descending mode; and (c) schematic representation of each low resolution parcel for which the ground motion is estimated.

Figure $4 \mathrm{~b}$ shows the SAR amplitude scene obtained by averaging the 68 images after precise co-registration to a single master (18 January 1997), in preparation for the multi-temporal interferometric analysis.

Multi-temporal image processing of the 68 single look complex scenes was carried out using the GAMMA SAR and Interferometry software (GAMMA Remote Sensing and Consulting AG, Gümligen, Switzerland) and using the low resolution Small Baseline Subset (SBAS) approach developed by Berardino et al. [10]. This method is based upon the generation of a set of small baseline interferograms between the satellite scenes acquired during each repeat pass, by selecting only those that are separated by less than $250 \mathrm{~m}$ perpendicular baseline and three years temporal baseline. This is to minimise the presence of temporal and spatial phase decorrelation components in the generated interferograms and enhance phase quality of the processed pixels (hence interferometric coherence).

Multi-looking factors of 4 in the range direction and 20 in the azimuth direction were employed to process the input single look complex scenes, in order to increase the phase signal quality and reduce radar speckle. This increased the corresponding size of the image pixels to $\sim 85-90 \mathrm{~m}$, corresponding to $\sim 100 \mathrm{~m}$ on the ground. Interferograms were formed based on the small baseline pairs of scenes, and initial topographic information was subtracted from the latter using information from NASA's Shuttle Radar Topography Mission (SRTM) elevation model at $90 \mathrm{~m}$ resolution. A coherence threshold of 0.25 was used for the selection of the image pixels of a suitable quality for the ground motion analysis, and phase information from the stack of small baseline interferograms was processed for these pixels only. Orbital phase ramps removal and phase unwrapping of the differential interferograms followed. Interferograms with unwrapping errors were excluded from the analysis. Least squares covariance analysis of the unwrapped phases then allowed the computation of annual velocity estimates and associated standard errors, and improved height information. Full deformation time series, for the network of coherent pixels, were subsequently derived as per [10], by exploiting the singular value decomposition approach to retrieve a minimum-norm least squares solution for the phase of each pixel at each acquisition time. To remove atmospheric delay components, a cascade of a high-pass filter in time and a low-pass spatial filter was also used. The estimated phase values were finally converted to deformation via multiplication by $\lambda / 4 \pi$. 
The reference point to which all ground deformation estimates were referred was a location within a geologically stable area in Belfast, which was also characterised by high interferometric coherence $(54.59 \mathrm{~N},-5.94 \mathrm{E})$.

The processing results were exported in the form of a point-wise database, including a set of 36,791 points, each representing a parcel of land of around 100 by $100 \mathrm{~m}$ on the ground (Figure $5 \mathrm{c}$ ). For each point, the database includes: unique ID, latitude and longitude in the 1984 World Geodetic System (WGS84) datum, annual velocity estimated along the satellite LOS and its standard error, elevation expressed in metres above the Earth Gravitational Model 1996 (EGM96) ellipsoid, average coherence of the point, ranging from 0 (no coherence) to 1 (perfect coherence), plus a series of 68 values, indicating the position of the point at each date.

Accounting for the extent of the processed area $\left(\sim 4200 \mathrm{~km}^{2}\right)$, the average density of targets identified consists of approximately 10 points per square $\mathrm{km}$, with sparse coverage across rural areas and very dense networks of targets over built-up areas such as Belfast and Bangor (Figure 6), where over 140 points per square $\mathrm{km}$ were found. This coverage reflects the presence of coherent areas from which radar backscattering is kept during the repeat passes. The resultant contrast in density in urban compared with rural areas is only to be expected.

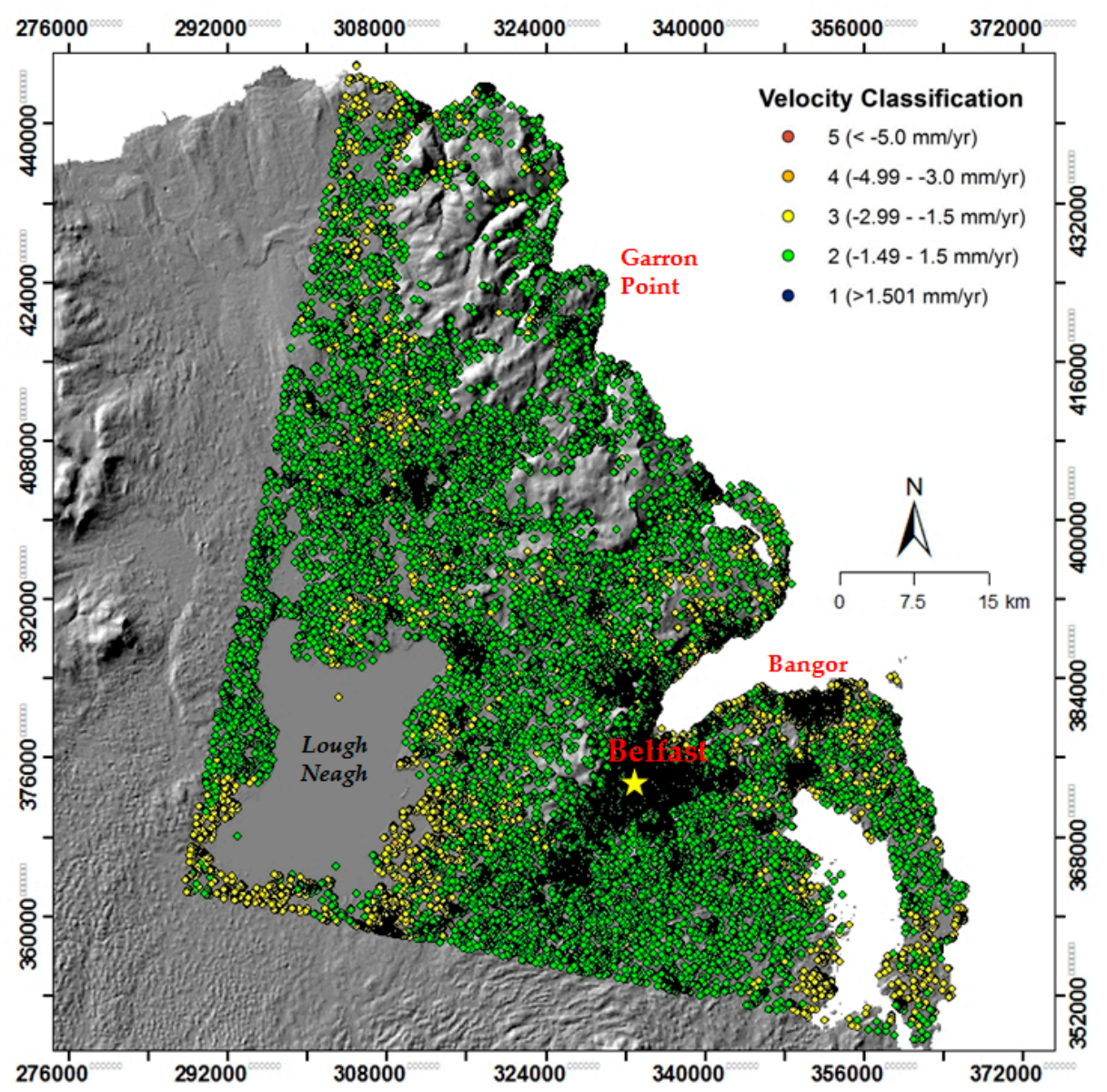

Figure 6. Ground deformation dataset obtained after Small Baseline Subset (SBAS) Satellite Interferometric Synthetic Aperture Radar (InSAR) processing of the ERS-1/2 data stack for 1992-2000, overlapped onto shaded relief of NASA's Shuttle Radar Topography Mission (SRTM) elevation model at $90 \mathrm{~m}$ resolution made available by CGIAR-CSI. Data are displayed according to the observed annual velocity as estimated along the satellite LOS. Negative values indicate motion away from the sensor ( subsidence), whilst positive values indicate motion towards the sensor ( $\sim$ uplift). The yellow star indicates the location of the reference point. 
The results were converted from WGS84 to the Irish National Grid in a Geographic Information Systems (GIS) environment. A simple classification of the results based on their annual LOS velocity, VEL, was adopted. The symbology for the velocity classes was defined from the ERS- $1 / 2$ data range (i.e., -6.30 to $1.69 \mathrm{~mm} /$ year) and defined in five classes as: (1) $V E L>+1.501 \mathrm{~mm} /$ year; (2) $-1.49<V E L \leq+1.50 \mathrm{~mm} /$ year; (3) $-2.99<V E L \leq-1.50 \mathrm{~mm} /$ year; (4) $-4.99<V E L \leq-3.00 \mathrm{~mm} /$ year; and (5) $V E L \leq-5.00 \mathrm{~mm} /$ year.

Figure 6 provides an overview of the coverage of the processed ERS-1/2 1992-2000 SBAS results. The density of points in the area immediately to the south of Belfast Lough appears black due to the greater density of points in this area.

\subsection{SUAV Surveying and VHR Surface Modeling}

Unmanned Aerial Vehicles (UAV) are increasingly used in engineering geology and physical geography for the acquisition of low-altitude aerial photography and for the generation of high resolution elevation models, to study geomorphologic processes such as landslides, soil erosion and coastal processes (e.g., [11-14]). Recent applications in areas of open-pit mines have also proved the potential of UAV-derived elevation models to characterise geomorphic features (e.g., [15]).

For our study, we utilised a man-portable, namely Small UAV (SUAV) system, using an X8 rotor configuration for added flight redundancy. An autonomous flight plan campaign was designed to acquire Very High Resolution (VHR) aerial imagery of the Maiden Mount salt mine collapse at Carrickfergus, an embankment slope and surrounds at Ligoniel Park in Belfast and historic salt mine works at Salt Hill in Carrickfergus.

The first campaign took place on 10 May 2016 at Maiden Mount to collect Red-Green-Blue (RGB) and Near Infra-Red (NIR) imagery using the X8 airframe by 3DR Robotics (Berkeley, CA, USA). Two fully autonomous flights were undertaken based on a pre-programmed 'lawn-mower pattern' flight plan designed to insure image footprint over-laps of $85 \%$ and side-laps of $75 \%$ at a flight level of $60 \mathrm{~m}$ above ground level and capture speed of $\sim 6 \mathrm{~m} / \mathrm{s}$.

Pre-flight ground surface distance was calculated at $\sim 1.9 \mathrm{~cm}$ for RGB collection and $\sim 2 \mathrm{~cm}$ for NIR image collection. Flight one collected colour imagery utilising a gimbal fixed compact digital single lens reflex camera (i.e., Sony A5000, 16 mm Pancake lens, Sony Corporation, Tokyo, Japan), the second flight acquiring supplementary 3 band NIR imagery (i.e., hot swapping a MAPIR NIR camera system, San Diego, CA, USA). RGB camera capture and shutter settings were controlled by the on-board PixHawk flight controller (ETH, Zurich, Switzerland) auto-calculated for optimum distance/overlap. NIR image capture was controlled using an $3 \mathrm{~s}$ intervalometer script.

To allow for accurate georeferencing of ortho-image (RGB \& NIR) and surface models outputs, Ground Control Points (GCPs) in the form of temporary survey checker boards were distributed in scene and surveyed to the Irish Grid 1975 Polynomial / OSGM02 local grid and datum using Network Real Time Kinematic (NRTK) Global Navigation Satellite System (GNSS) methods with a Leica Viva GS15 receiver (Wetzlar, Germany). Six GCPs were surveyed and positioned to $\sim 10 \mathrm{~mm}$ horizontal and $\sim 15 \mathrm{~mm}$ vertical relative accuracies.

We collected $\sim 140$ close range aerial photographs (RGB/NIR) over the site and processed them to create a VHR ortho-photograph, a photogrammetry-derived dense point cloud and Digital Surface Model (DSM), using a Structure from Motion (SfM) computer vision approach (e.g., [16,17]) computed with AgiSoft PhotoScan Professional software (Educational Licensing; Agisoft LLC, St. Petersburg, Russia). The SfM approach is a multi-view stereo photogrammetric range imaging technique aimed to estimating three-dimensional (3D) structures from two-dimensional (2D) image sequences, usually acquired from a moving platform. The approach does not require the use of expensive equipment, specialist expertise or extremely long processing times, and can allow the generation of 3D point clouds of vertical accuracy of a few centimeters (e.g., $5 \mathrm{~cm}$ [17]). Its emergence has therefore revolutionised 3D topographic surveying in physical geography [16]. 
Our 140 photographs were combined via SfM into a 3D structure thanks to the identification and matching of features such as corner points (e.g., edges) that were imaged from different viewpoints and could be identified in a number of photographs. 3D position of the identified features and the motion path of the camera were reconstructed, and the GCPs were incorporated into the processing steps to generate accurate georeferenced data projects in both plan and local datum (i.e., Ordnance Datum Belfast Lough).

The final SUAV-derived VHR ortho-photograph has a pixel resolution of $1 \mathrm{~cm}$, and covers a 200 by $300 \mathrm{~m}$ area (Figure 7). A secondary NIR ortho-photo has a pixel resolution of $2 \mathrm{~cm}$. Similarly, the resulting mesh based on the dense point cloud, at full resolution, includes over 4,504,000 vertices and 9,000,000 faces and has been used as the basis for the creation of the DSM, ortho-rectification of the aerial photography and 2D/3D visualisations in AgiSoft PhotoScan and a GIS. As with the RGB ortho-photograph, the output elevation model has a spatial resolution of $1 \mathrm{~cm}$ (Figure 8). It is worth noting that the generated DSM depicts elevation information of the top surface of the investigated area, including elements above the surface, such as trees, grass and fences, as can be seen in Figure 8 .

A low resolution SUAV-derived DSM (RGB mapped) was also created and made freely available for 3D displaying and download via the SketchFab platform (New York, NY, USA). Similarly, full resolution web-views of the VHR aerial ortho-photographs have been made available via DroneLab (Drone Industries Ltd, Newcastle upon Tyne, UK) (Appendix A).

A return SUAV campaign at the same site was carried out on 16 June 2017, using a cross grid flight method and collecting 300 close range aerial photographs that, as done for the first campaign, were processed to generate a VHR ortho-photograph and a photogrammetry-derived DSM.
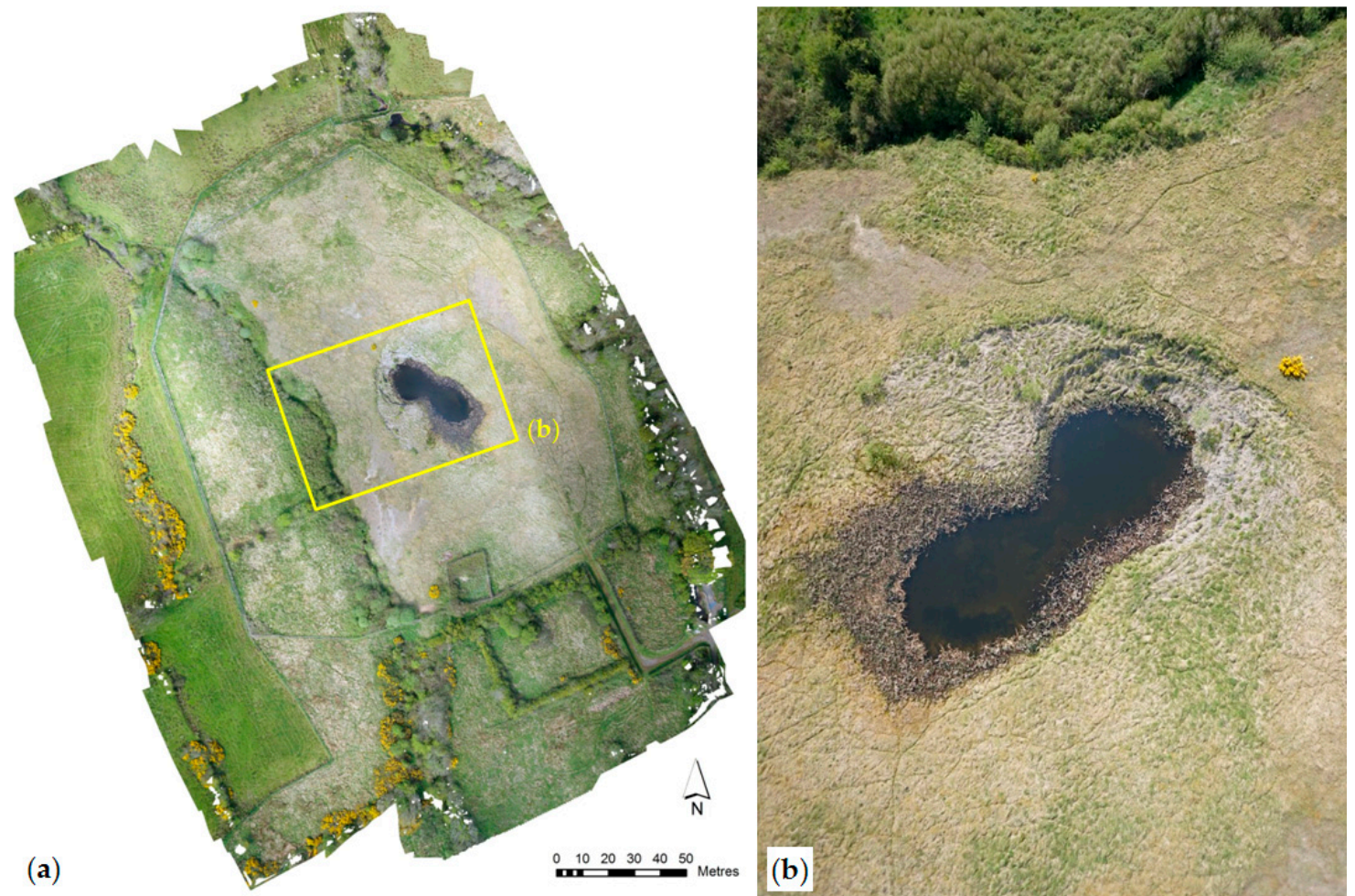

Figure 7. (a) Small Unmanned Aerial Vehicle (SUAV)-derived Very High Resolution (VHR) ortho-photograph and (b) close-up of the Maiden Mount salt mine collapse, derived based on data acquired during the 10 May 2016 campaign.

Identical flights, SfM processing, and return campaigns are to be carried out at the other target sites as well, to test the SUAV method as a means to detect local ground movement and displacements 
between flights and data capture. Whilst the latter will be subject of future research, in this paper we use the first SUAV-derived products for Maiden Mount as a test case to demonstrate that VHR optical and topographic surveying with SUAV systems can be integrated with satellite surveying to complement regional scale analyses of ground stability when there is a lack or sparse coverage of radar targets in the investigated area, or it is necessary to identify surface indicators of instability at a much finer spatial scale - though with lower vertical accuracy than a satellite-based investigation with multi-temporal InSAR (see Section 4.1).

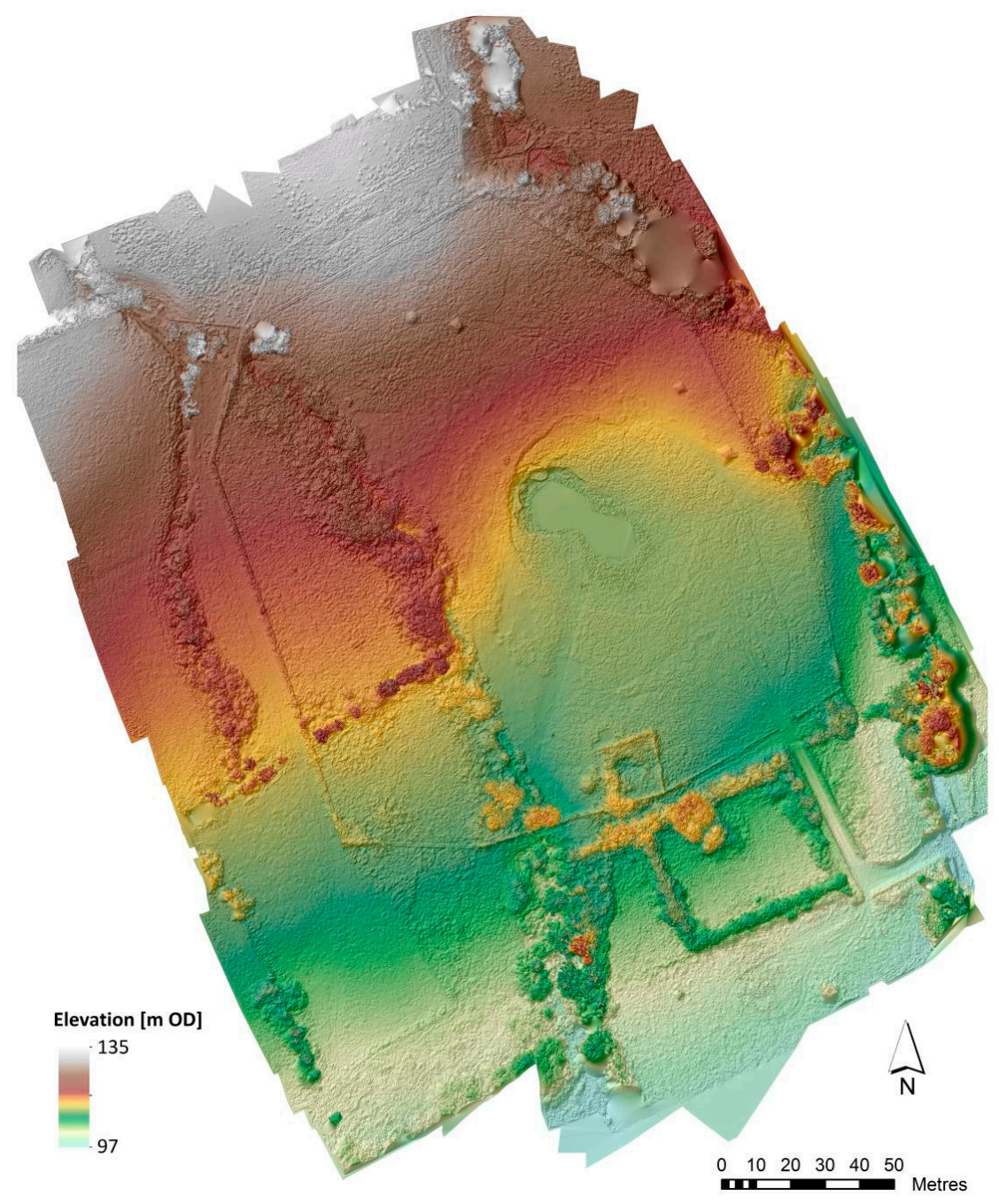

Figure 8. SUAV-derived VHR digital surface model of the Maiden Mount salt mine collapse, derived based on data acquired during the 10 May 2016 campaign.

\section{Results and Discussion}

By observing the areas of interest, as well as other areas that exhibit significant rates of ground deformation, we can develop a model of regional ground motion, characterising, for example, geotechnical phenomenon such as, consolidation settlement, dewatering and slope failure. In order to constrain the signatures more closely, the InSAR results can also be compared with physical monitoring datasets, such as groundwater levels, repeat ground based geomatics, or repeat scans of specific sites, as well as analysis of VHR ortho-photographs and DSM.

The following sections firstly explore the data associated with the stakeholder sites and subsequently attempt to provide a geological/geotechnical interpretation for the highest ground motion rates observed. The data are reviewed to firstly identify the density of results, and the rates 
and pattern of motion in the area of the key stakeholder sites (see Sections 4.1-4.5). For each site, a summary of the geological context and brief discussion is provided. Secondly, the data are assessed more broadly to identify the principal areas of ground movement revealed by this dataset and an interpretation of the causes for the observed deformation is presented. Analysis of the SUAV-derived ortho-photographs and DSM for the Maiden Mount mine collapse showcases how such VHR products can aid interpretation of localised ground instability in rural sites (Section 4.1).

Visual inspection of Figure 6 reveals variable movements in many of the known landslide areas while also highlighting motions associated within areas of historic mining activity. The results further identify a number of areas of interest that are displaying subsidence, potentially as a result of groundwater abstraction, soil compaction and shrink-swell processes.

It is worth noting that the use of a single reference point for the whole processed scene (see Section 3.1) might have caused propagation of some uncontrolled offsets across regions of the scene that are not very well connected, such as in the south-west corner of the processed scene (Figure 6). In this sector, narrow areas of land bound Lough Neagh to the west and to the south, thus increasing the risk of offsets in the estimated motion to occur. Inspection of the results against geological data, however, confirmed that the LOS deformation of -1.5 to $-2 \mathrm{~mm}$ /year observed in this area is plausibly linked to compaction of superficial deposits (mainly peat, lacustrine deposits, till and alluvium).

\subsection{Salt Mines in Carrickfergus}

The town of Carrickfergus sits on the south-eastern edge of the Antrim Plateau on a low lying coastal plain rising to the west reaching a height of $275 \mathrm{~m}$ at Knockagh. The superficial geology is dominated by till and tidal flat deposits of clay and sand (Figure 3 and Table 1).

The bedrock geology is characterised by Triassic Mercia Mudstone Group (MMG) on the coastal plains and lava flows of the Lower Basalt Formation (LBF) at elevation towards the north-west. Between these two dominant strata are Cretaceous chalk and glauconitic sandstone sequences of the Ulster White Limestone Formation (UWLF) overlying Jurassic Waterloo Mudstone Formation (WMF) which occur at elevations above $100 \mathrm{~m}$. A spring line is formed at the contact between the UWLF and impermeable WMF giving rise to extensive slope instability along the foot of the scarps. The scarps are dominated by talus aprons containing basaltic and limestone material. A number of N-S trending faults cut across the greater Carrickfergus area.

The town rests almost entirely upon MMG which, from an engineering perspective, has a high bearing strength. It is a fine grained mudstone with silty horizons. Gypsum occurs in veins and anhydrite as irregular nodules. Halite beds occur in the lower sequences of the MMG ranging in thickness from 1 to $40 \mathrm{~m}$. This economic commodity was extracted by both conventional mining techniques and solution methods.

Table 1. Reference summary geology for the Carrickfergus mines area.

\begin{tabular}{cccc}
\hline Age & Group/Formation & Acronym & Lithology \\
\hline Quaternary & Tidal Flat deposits; Till & & Chalk \\
Cretaceous & Ulster White Limestone Formation & UWLF & Grey mudstone with thin limestone beds \\
Lower Jurassic & Waterloo Mudstone Formation & WMF & Dark grey mudstone \\
Triassic & Penarth Group & PNG & Red and green mudstone and marl with thick \\
Triassic & Mercia Mudstone Group & MMG & sands \\
\hline
\end{tabular}

Rock salt mining began in the Woodburn area of Carrickfergus in the early 1850s, when a bed of rock salt at $\sim 170 \mathrm{~m}$ depth was discovered at Duncrue, $\sim 3 \mathrm{~km}$ north-west of the town, and a mine was developed and operated by the Belfast Mining Company. In only a few years, the mine reached a salt production rate of 20,000 tons/year. Other sites such as Burleigh Hill, French Park and Maiden Mount were later opened (in 1852, 1870 and 1877 respectively), and continued to operate after the closure 
of Duncrue in 1870, and until the late 1950s when the last of the old mines closed. Salt mines in this area were created using the 'pillar and stall' method, with large pillars of salt of about some metres in width and depth (e.g., $7 \mathrm{~m}$ by $5 \mathrm{~m}$ ) standing at intervals to support the roof of the excavated galleries, characterised by levels of 4-5 m height. The two mines Maiden Mount and French Park became connected due to brining operations at depth in later years, hence they now technically constitute one unique mine. The overall extent of the fenced-off zone over the mine (determined from modelling the zone of influence for collapse) is around $0.14 \mathrm{~km}^{2}$.

Currently there are eight inactive and one active salt mine within the town of Carrickfergus. The inactive mines, which were subject to solution mining, have left a legacy of instability over large areas with a large number of crown holes developing and significantly affecting public safety and infrastructure (Figure 2a). The subsurface voids formed by galleries and dissolution processes pose a hazard if upward propagation results in subsidence at the surface. In the area of Carrickfergus, unstable salt mines have been frequently subject to collapse, thus creating sinkholes on the ground and sometimes development of large ponds. An example is the collapse that occurred at the site of Maiden Mount on 19 August 2001, which generated a large surface hole of over $50 \mathrm{~m}$ in diameter and several metres depth (Figure 9a,c) that was subsequently filled artificially to reduce risk, but resulted in a much larger surface depression that altered the local topography.
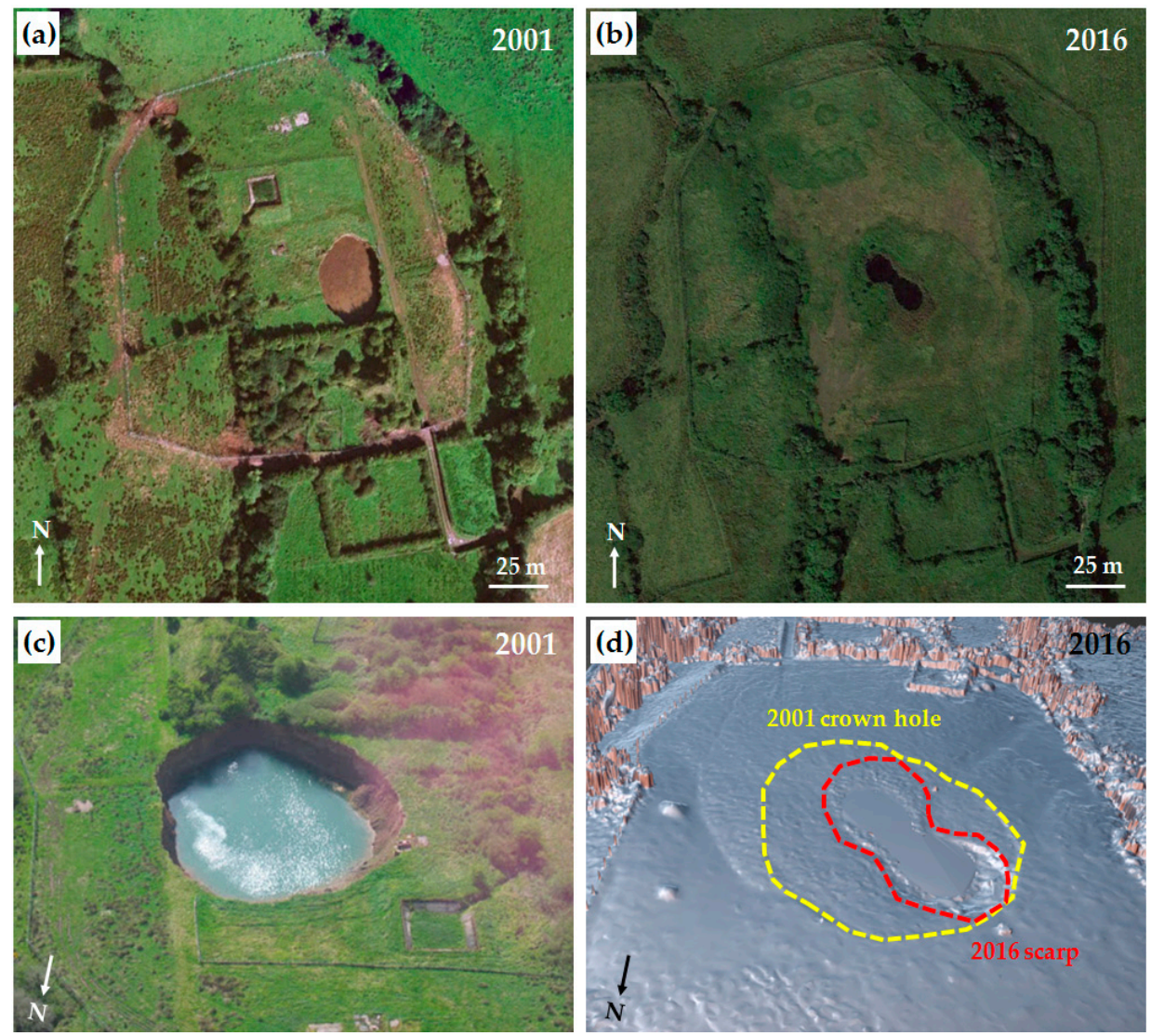

Figure 9. Satellite images of the area of the Maiden Mount salt mine collapse at Carrickfergus from Google Earth on (a) 31 December 2001 (c) 2017 The GeoInformation Group and (b) 16 August 2016 (c) 2016 Google; (c) aerial view of the 2001 crown hole collapse (c) Crown Copyright; and (d) shaded relief of the VHR Digital Surface Model (DSM) with indication of the 2001 crown hole and a more recent scarp formed in the filling material.

The density of SBAS results within the area of interest of the Carrickfergus salt mine sites is limited, with only 3 targets found about 150 m east of the Maiden Mount shafts (i.e., two yellow 
and one green points in the centre of Figure 10a) and none around the area of the French Park shafts. They all indicate relatively stable conditions, with a maximum annual velocity of $-1.7 \mathrm{~mm} /$ year over the monitoring period. More significant is that the time series in Figure 10b shows a steady trend of downward ground motion of at least $15 \mathrm{~mm}$ over the period 1992-2000.

For this study area, results from the InSAR analysis offer a somewhat limited potential due to the sparse coverage of reflectors and time series data. This poor coverage is mainly due to the rural land cover of the site and presence of vegetation, which are factors that generally cause temporal decorrelation and loss of InSAR coherence. When assessing land stability, the natural distribution and density of radar reflectors may not be sufficient to provide enough information for the problem under consideration. The low number of reflectors and limited information on ground motion in this area has therefore prevented the identification of a detailed ground stability baseline scenario for this region. Therefore, the integration with other data sources and VHR becomes necessary and useful for the analysis of localised ground instability and the assessment of hazard. In these cases, artificial reflectors (e.g., corner reflectors) to deploy across the investigated area might be used to locate monitoring targets at the desired locations.

Figure 7 shows the SUAV-derived VHR ortho-photograph and a close-up of the Maiden Mount salt mine collapse, derived based on the data acquired during the 10 May 2016 campaign. Figure 8 also shows the derived DSM, where the original crown collapse occurred in 2001 can be easily recognised around the current water pond. Elevations in the SUAV-derived DSM range between 97 and $135 \mathrm{~m}$ OD. It is worth noting that the SUAV campaigns focused on the Maiden Mount site only (i.e., a $0.06 \mathrm{~km}^{2}$ survey area), whilst the overall extent of the zone of influence for collapse-including the French Park mine-is much greater than that shown in the SUAV ortho-photograph in Figure 7, as discussed above.

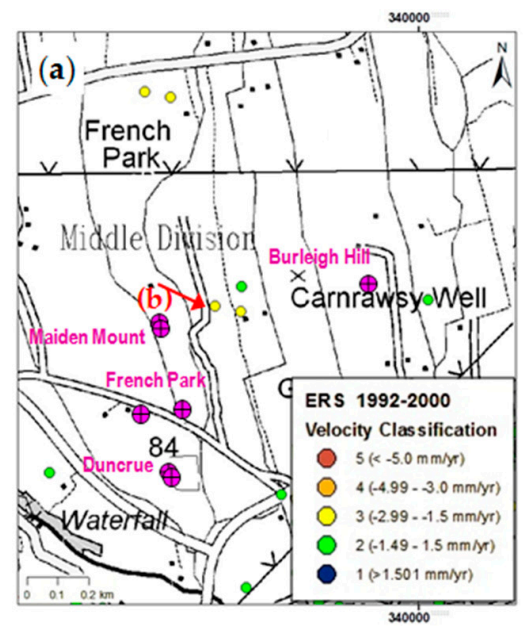

(b)

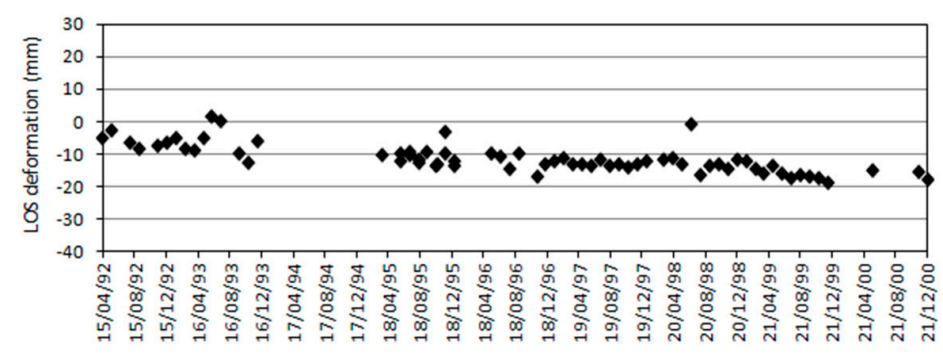

Figure 10. (a) Observed ground deformation and (b) time series for 1992-2000 in the area of the French Park and Maiden Mount salt mines in Carrickfergus. Mine shafts are indicated and labelled in pink. Reproduced from Land and Property Services data with the permission of the Controller of Her Majesty's Stationery Office, (C Crown copyright and database rights MOU203.

Despite the presence of vegetation in the area of the 2001 collapse, during both the SUAV campaigns ground deformation features could be seen in the ortho-photograph and DSM (Figure 9d), as well as in a lower resolution satellite image acquired in August 2016 and available through Google Earth (Figure 9b). These data all confirm the conditions of the area which is in current restricted access state after the remediation and stabilisation works that took place after the original collapse occurred in 2001 (Figure 9a,c). Figure 11 also compares the VHR ortho-photographs obtained from the 10 May 2016 and 16 June 2017 SUAV campaigns and reveals not only significant increase in the vegetation cover and water level from 2016 to 2017 (which might be justified by the difference in the 
acquisition months, May and June, weather and soil moisture conditions), but also the occurrence of further ground settlement at the south-western edge of the pond, where a $\sim 5 \mathrm{~m}$ wide and $\sim 15 \mathrm{~m}$ long strip of deeper waters can be observed.

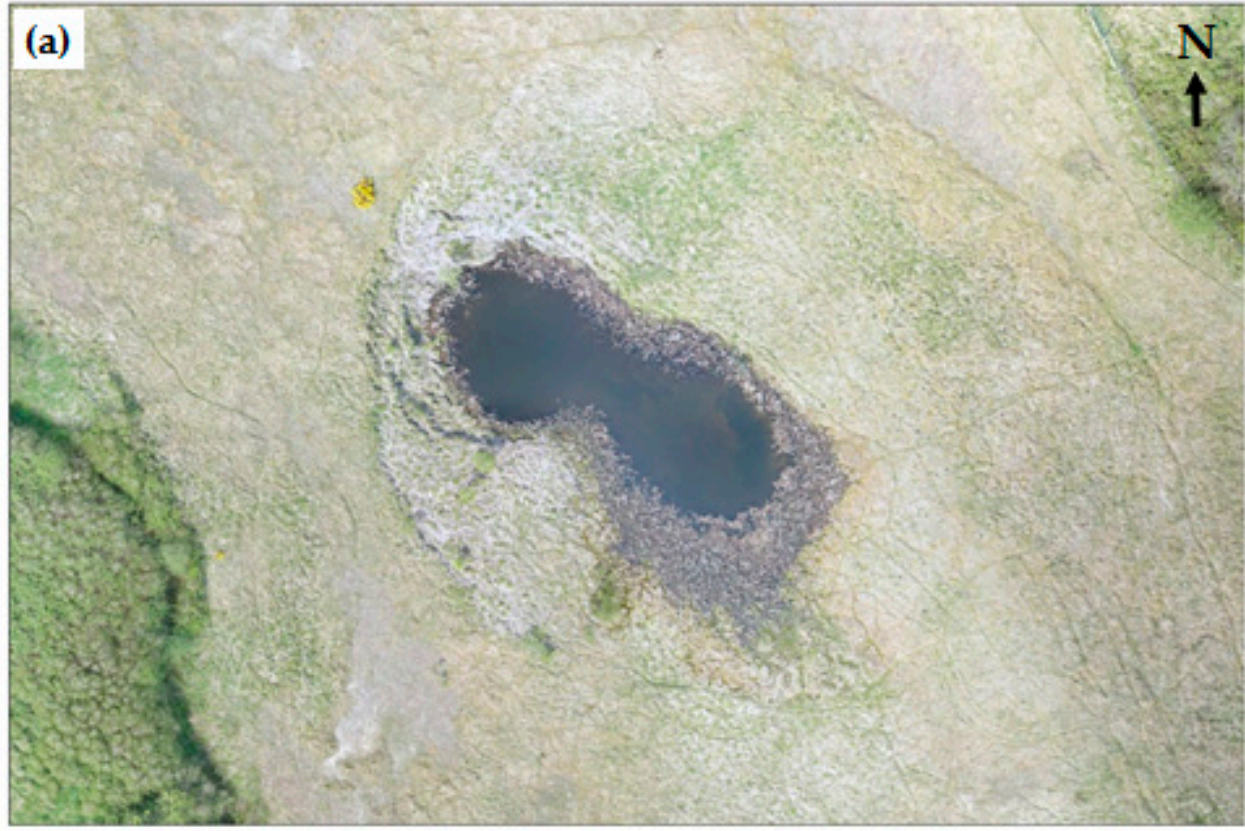

$10 / 5 / 2016$

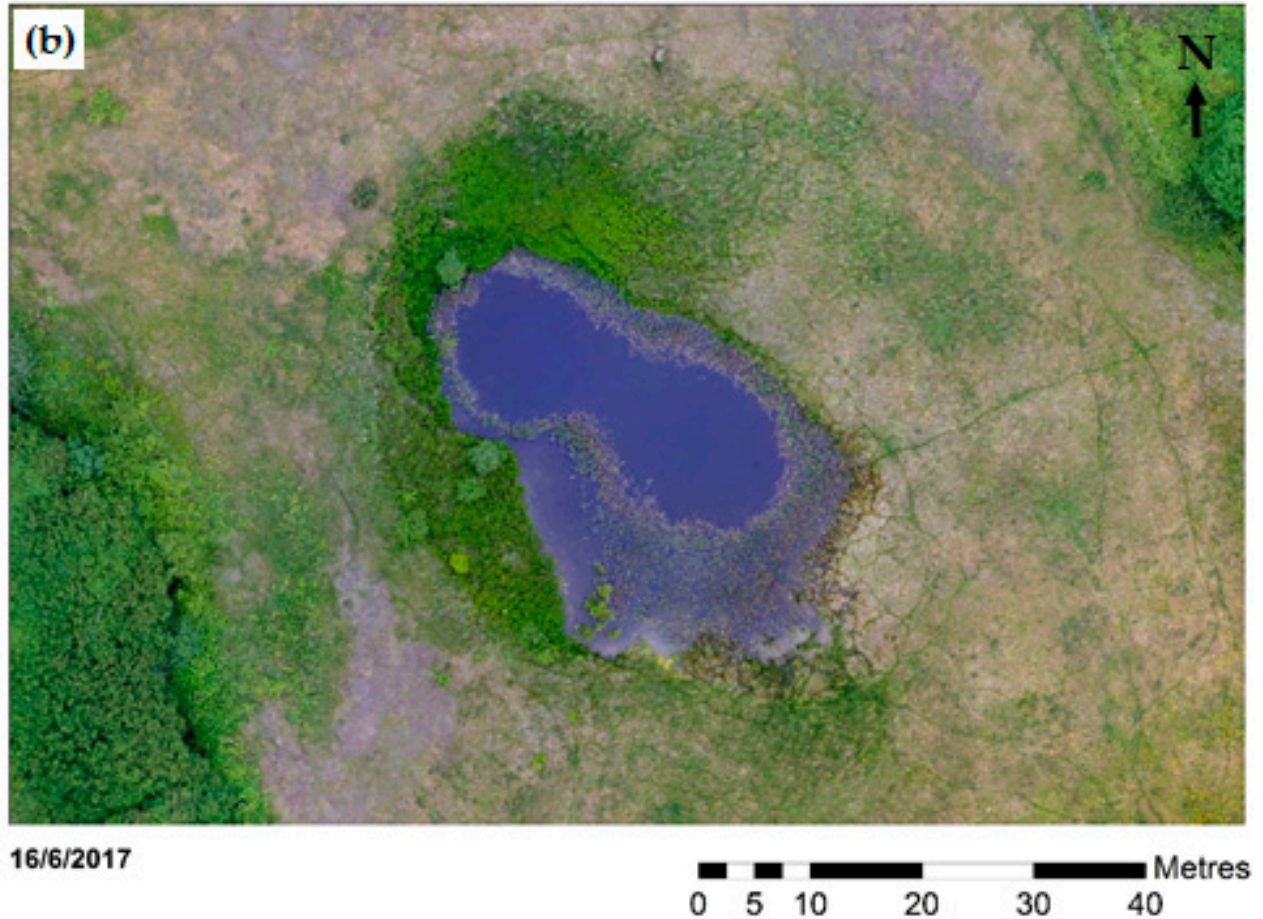

Figure 11. Comparison between VHR ortho-photographs from the (a) 10 May 2016 and (b) 16 June 2017 SUAV campaigns carried out at the Maiden Mount salt mine collapse at Carrickfergus.

Although a low density of InSAR targets was found in this area, some observations could be drawn in relation to the motion measured for the 3 targets located to the east of the site (just off the modelled zone of influence for collapse) and their time series (see Figure 10). Considering the date of the collapse (2001) and temporal span of the InSAR data, it might be possible-in theory-to relate the 
motion seen by the 1992-2000 InSAR analysis with the main event. In this case, however, it is difficult to identify precursors of the 2001 collapse based on analysis of the time series and the derivative of the deformation rates, as the pixels reveal an almost steady deformation trend throughout the monitoring period.

To further investigate instability in this area, other monitoring data collected from the abandoned salt mine sites at Carrickfergus in the past two decades were obtained and collated. The Department for the Economy provided extensometer, ground levelling and groundwater level data. The shafts and adits database maintained by the Geological Survey of Northern Ireland was also used to verify areas of known mine workings including recorded collapses or noted subsidence. These data were collated and time series sequences created to determine the rate of motion and water table levels at specific points within Carrickfergus. Together with the Department for the Economy sonar cavity data, they identify areas of minimal mine supports that are subsiding at a greater rate than areas of greater support while the water level is significantly influencing brine seepage events close to a public water supply intake.

Precise ground levelling station data and magnet extensometer collected from the French Park and adjacent Maiden Mount mines during the time period 1992-2000 showed differential motion across the surface with annual creep rates ranging from $1.0 \mathrm{~mm}$ /year to $10.00 \mathrm{~mm} /$ year. The greater of these movements were concentrated along the central sections of the site directly above the main underground works where sonar cavity surveys indicated the erosion of pre-existing support pillars. Groundwater level measurements for the same period showed little variation in levels indicating that. Situated $3 \mathrm{~km}$ to the east are the Carrickfergus/International salt mines. Precise ground levelling data collected at this site showed a trend of downward movement where significant creep rates of up to $40 \mathrm{~mm}$ /year were recorded. The rates of motion were steady throughout the time period 1992-2000 (as also observed from the analysis of the InSAR results) with the greatest creep rates associated with the areas close to the mine shafts.

\subsection{Belfast-Bangor Railway Line}

Operated by Northern Ireland Railways, the double-track Bangor-Belfast railway line (Figure 2b) is part of the key link into Belfast city centre, serving key assets of the city such as the Ulster Museum and George Best Belfast City Airport.

The line crosses a number of geological lithotypes. The area is one of low lying coastal plain with some reclaimed land between Belfast and Holywood. Superficial deposits are largely composed of diamiction sand and gravel deposits to the east with glaciofluvial, ice contact deposits of sand, gravel and boulders becoming prominent to the west (Figure 3 and Table 2). The superficial deposits rest on bedrock that is dominated, at its eastern extent, by Ordovician-Silurian greywacke and shale with a number of small blocks of Carboniferous and Triassic sandstones to the west. A number of NNW-SSE trending faults occur associated with the Carboniferous and Triassic blocks.

Table 2. Reference summary geology along the Bangor to Hollywood Railway line.

\begin{tabular}{|c|c|c|}
\hline Age & Group/Formation & Lithology \\
\hline Quaternary & Till; Glacial Sands and Gravels & Diamicton; sand and gravel \\
\hline Triassic & Belfast Group & Marl with gypsum, dolomitic limestone and basal sandstone \\
\hline Carboniferous & Holywood Group & Red conglomerate and sandstone with thin mudstones \\
\hline Ordovician & $\begin{array}{l}\text { Gilnahirk Group; including } \\
\text { Helens Bay Formation }\end{array}$ & Greywacke and shale; Shale and pillow lava \\
\hline
\end{tabular}

Satellite InSAR monitoring of a high speed railway in China and validation with geodetic levelling has shown the potential of remotely sensed data to identify regional patterns of land motion that could affect the accessibility and safety of the lines (e.g., [18]). In this regard, the analysis of InSAR 
data within buffer zones around the railway track can ease the identification of critical sections of the infrastructure.

In our study, the narrow, heavily vegetated Belfast-Bangor railway line has generated a higher density of SBAS results than might have been anticipated (Figure 12a). The coverage reflects the distribution of the different land cover types across the region, with much denser networks of targets in the urbanised portions of the line, and sparser coverage where the vegetation is dense.

The rates of movement in 1992-2000 were moderate and zoned around the central area of Bangor $(349,638 ; 381,583)$. In this sector, ground motion velocities reached $-3.2 \mathrm{~mm} /$ year, but were generally in the order of -1.0 to $-2.0 \mathrm{~mm}$ /year for most of the identified targets. Some of the time series (Figure 12b) indicated a general rise in ground level between mid-1993 and 1995, followed by stability until 1998 and then a gradual fall. This may reflect long-range seasonality in moisture in the tills and warrants comparison with historic climate data. Alternatively, there may be an underlying anthropogenic reason, for instance associated with maintenance and subsequent settlement of the track.

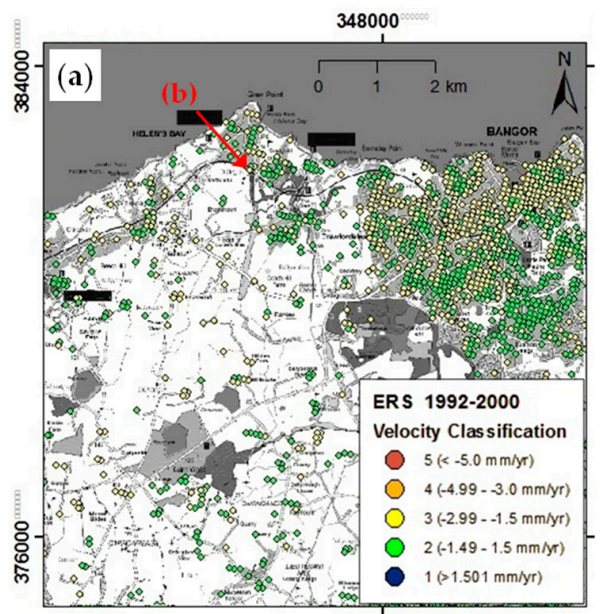

(b)

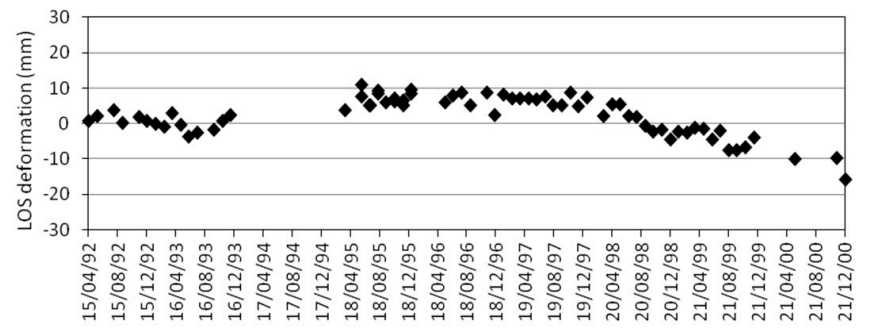

Figure 12. (a) Observed ground deformation and (b) time series for 1992-2000 in the area of the Belfast-Bangor railway line at Skelly Hill. Reproduced from Land and Property Services data with the permission of the Controller of Her Majesty's Stationery Office, (C) Crown copyright and database rights MOU203.

\subsection{Throne Bend and Ligoniel Park}

Throne Bend lies at the northern boundary of Belfast in a highly populated area and is one of the busy arterial routes into Belfast. Elevated above $80 \mathrm{~m}$ the area is underlain by the Triassic MMG and the Sherwood Sandstone Group close to the boundary with the overlying Jurassic mudstones, Cretaceous chalk and the LBF (Figure 3 and Table 3).

Table 3. Reference summary geology in the Throne Bend area.

\begin{tabular}{cccc}
\hline Age & Group/Formation & Acronym & Lithology \\
\hline Quaternary & Till & & Basalt \\
Palaeocene & Lower Basalt Formation & LBF & Chalk \\
Cretaceous & Ulster White Limestone Formation & UWLF & Grey mudstone with thin limestone beds \\
Lower Jurassic & Waterloo Mudstone Formation & WMF & Dark grey mudstone \\
Triassic & Penarth Group & PNG & Red and green mudstone and marl with thick \\
Triassic & Mercia Mudstone Group & MMG & salt bands \\
\hline
\end{tabular}

Large Pleistocene landslide structures with flat areas composed of massive slump blocks displaced from the Antrim Plateau dominate the topography. Below the steep edge of the slumped blocks, the 
surface is dominated by landslide material composed of mudstones, sandstones, chalk and basaltic material. Incipient instability within slide debris has been recorded during excavation work on local developments [19] and roads and localised cracking of buildings and walls is evidence that some movement is still occurring within the area.

The geological setting of Ligoniel (Figure 2c) is very similar to that of Throne Bend. Lying to the north-west of the city and elevated at over $200 \mathrm{~m}$, the dominant bedrock lithology is that of MMG, which forms the bedrock to much of the development in Ligoniel (Figure 3 and Table 4). The area is adjacent to a steep escarpment of UWLF and LBF with a substantial thickness of landslip debris material. An area of particular interest is in a local park, where immediately to the north of a water dam, and the impermeable MMG boundary with the Hibernian Greensands occurs within a gentle slope at the boundary between the impermeable MMG and the Hibernian Greensands. It is likely, as noted in other areas, that this boundary will be a spring line, creating conditions conducive to surface movement. Movement within the park has been monitored, at the request of Belfast City Council since the early 1990s, due to concerns regarding the stability of a water dam positioned adjacent to the area of noted movement.

Table 4. Reference summary geology for the Ligoniel Park area.

\begin{tabular}{cccc}
\hline Age & Group/Formation & Acronym & Lithology \\
\hline $\begin{array}{c}\text { Quaternary } \\
\text { Palaeocene }\end{array}$ & Till & & Basalt \\
Cretaceous & Ulster White Limestone Formation & UWF & $\begin{array}{c}\text { Chalk } \\
\text { Triassic }\end{array}$ \\
Mercia Mudstone Group & MMG & $\begin{array}{c}\text { Red and green mudstone and } \\
\text { marl with thick salt bands }\end{array}$ \\
\hline
\end{tabular}

There is a relatively low density of reflectors in the Throne Bend area (see Figure 6), the same as the density observed in Ligoniel Park (Figure 13a). As observed for the other areas of interest, this reflects the land cover of these regions, which are mostly dominated by the presence of vegetation and absence of surface features acting as good radar targets and showing sufficient interferometric coherence.

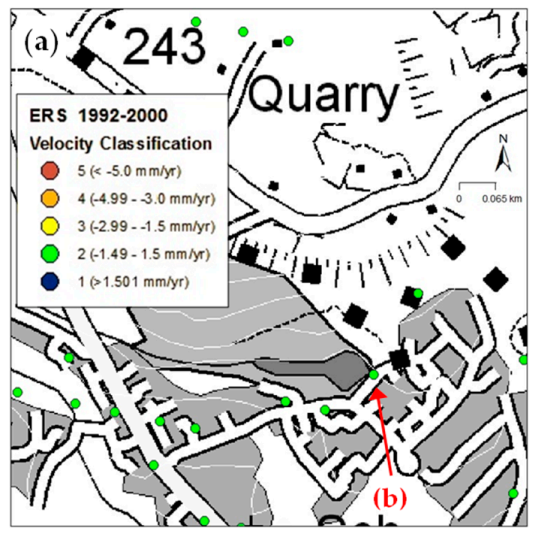

(b)

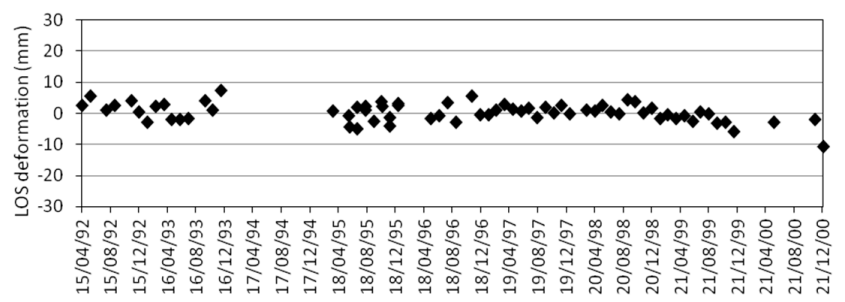

Figure 13. (a) Observed ground deformation and (b) time series for 1992-2000 in the area of Ligoniel Park. Reproduced from Land and Property Services data with the permission of the Controller of Her Majesty's Stationery Office, (C) Crown copyright and database rights MOU203.

The reflectors that have been identified indicate relatively stable conditions. Two points, one on the eastern perimeter of the Ligoniel Park and one to the northeast indicated $-0.81 \mathrm{~mm} /$ year at $(330,544 ; 377,691)$ and $-0.45 \mathrm{~mm} /$ year at $(330,464 ; 377,544)$ during the $1992-2000$ monitoring period.

The time series in Figure 13b confirmed the small magnitudes of the motion and did not show any significant nonlinear trend, albeit there appeared to be a more pronounced settlement or motion of ground levels after April 1999. On the other hand, in situ monitoring data from Belfast City Council 
data for Ligoniel Park have shown the presence of seasonal effects on ground motion at the location suggesting climatic parameters have an influence on the stability of the site.

\subsection{Straidkilly and Garron Point}

The Garron Point-Straidkilly area sits on the eastern side of the Antrim plateau and is characterised by deep valleys incised through glacial deposits and on its eastern margin large scale rotational landslip blocks sitting at angles up to $70^{\circ}$. The superficial geology is predominantly glacial tills and, in upland areas, peat. Much of the slope is covered by talus composed of basalt and chalk derived from the bedrock.

The bedrock geology is dominated by sequences of Palaeogene basalt flows of the Antrim Lava Group (ALG) overlying white Cretaceous chalk (Figure 3 and Table 5). Inland, only the basalt sequences are exposed while on the coastal sections the high angle of the rotational features exposes the entire stratigraphy down to the MMG (Figure 14). The lithology and structure combine to make the area highly susceptible to landslides. Fractures within the basalt and chalk act as pathways for water infiltration to the impermeable mudstones giving rise to a number of mudslides often affecting the coastal road.

Table 5. Reference summary geology for the Garron Point area.

\begin{tabular}{cccc}
\hline Age & Group/Formation & Acronym & Lithology \\
\hline Palaeocene & Upper Basalt Formation & UBF & Olivine basalt lava \\
Palaeocene & Interbasaltic Formation & IB & Laterite, bauxite and lithomarge \\
Palaeocene & Lower Basalt Formation & LBF & Oasalt lava \\
Cretaceous & Ulster White Limestone Formation & UWLF & Chalk \\
Lower Jurassic & Waterloo Mudstone Formation & WMF & $\begin{array}{c}\text { Grey mudstone with thin } \\
\text { limestone beds }\end{array}$ \\
Triassic & Mercia Mudstone Group & MMG & $\begin{array}{c}\text { Red and green mudstone and } \\
\text { marl with thick salt bands }\end{array}$ \\
\hline
\end{tabular}

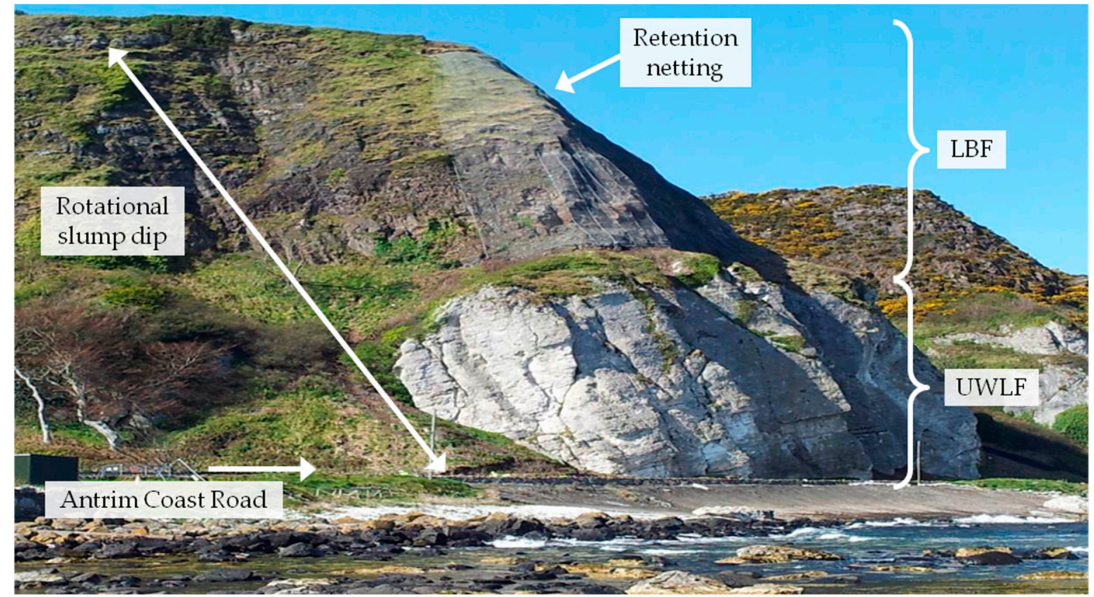

Figure 14. Slope instability at Garron Point. Photograph taken in 2012. Preventative measures that were put in place to minimise risk from rock-falls are indicated. UWLF: Ulster White Limestone Formation; LBF: Lower Basalt Formation.

The main feature identified in this area from the analysis of the InSAR data is at Caranure $(328,353 ; 425,197)$, which lies to the west of Garron Point. Here a single point reached ground motion velocity of $-3.1 \mathrm{~mm} /$ year. The surrounding points have been subject to LOS movement velocities of -1.5 to $-2.9 \mathrm{~mm} /$ year (Figure 15a). The movement might be associated with the presence of Crearlagh Burn river, which crosses this zone. It is located in an area of mapped mass movement. The steep topography and morphology of the unstable area suggest that the majority of the movement occurs 
along the vertical direction with minor horizontal components. Accounting for the direction of the satellite LOS in descending mode (i.e., oriented from east to west with a look angle of $23^{\circ}$ with respect to the vertical direction; Figure 5), the projection of the observed LOS motion onto the vertical direction would result in rates of -1.6 to $3.4 \mathrm{~mm}$ /year. The latter are obtained by dividing the LOS velocity values by the cosine of the look angle $\theta$ (hence, by 0.92 in this case). Alternatively, the computation of the velocity could have been performed by assuming the steepest slope direction as the most probable direction of motion, and therefore using the directional cosine of the LOS and slope to derive the correct value of the velocity for each pixel, as per [4].

The time series for Caranure appeared to provide evidence of the landslip that is known to have occurred in this area. The landslide database maintained by the Geological Survey of Northern Ireland records three landslides, one $200 \mathrm{~m}$ to the south and two $175 \mathrm{~m}$ to the east.

The movement during the period 1992 to 2000 (Figure 15b) comprises a strong trend of declining ground levels, commencing in December 1992 through to May 2000, with a number of superimposed steps of more rapid reductions in ground level. The largest of these occurred between April 1999 and May 2000 when there was a lowering of the ground surface of $16.6 \mathrm{~mm}$.

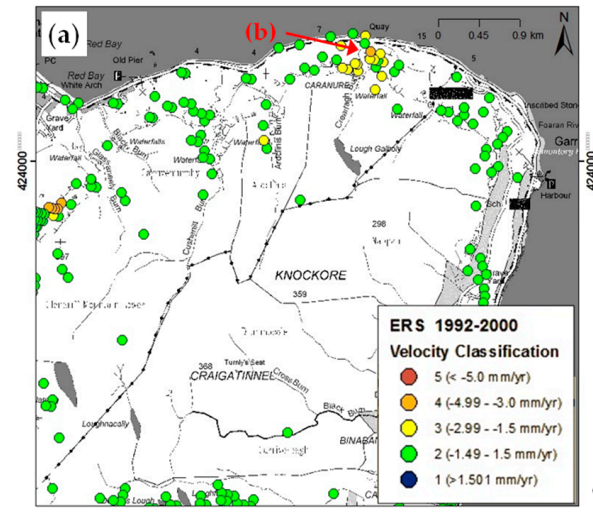

(b)

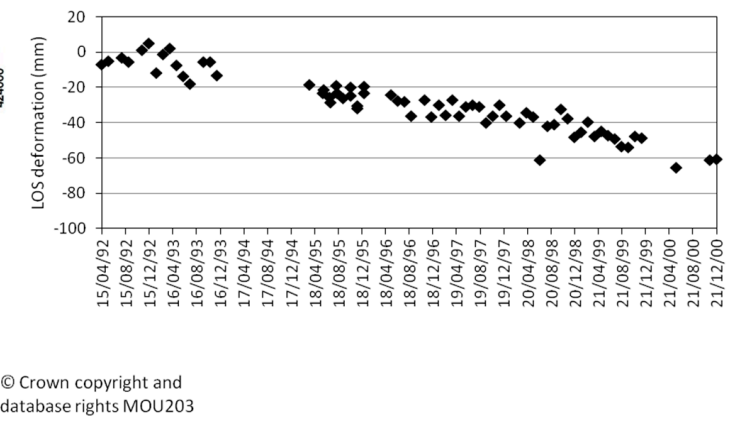

Figure 15. (a) Observed ground deformation and (b) time series for 1992-2000 in the area of Garron Point. Reproduced from Land and Property Services data with the permission of the Controller of Her Majesty's Stationery Office, (C) Crown copyright and database rights MOU203.

Landslide motions occurring along the east facing steep slopes of Garron Point are unlikely to be seen by the employed satellite data due to the geometry of the descending mode LOS of the ERS-1/2 satellites, and the presence of topographic distortions (mainly radar layover; e.g., [20]). In less steep but still east facing slopes, even in absence of radar layover, motions occurring along directions perpendicular to the satellite LOS are also undetectable, resulting in the presence of targets showing very low motion velocities (e.g., between $\pm 1.5 \mathrm{~mm}$ /year). In such areas, the use of the ascending mode stack of ERS-1/2 data might help to complement the analysis to capture ground motion along the west to east looking direction.

Farther north, centred on $(316,844 ; 443,189)$ near Doon, two additional points indicate another coastal landslide/rock fall on a steep escarpment. The points exhibit velocities of -3.0 and $-3.7 \mathrm{~mm} /$ year. The time series plot showed the long term lowering of ground level, followed by stabilization associated with a rise in ground level. There is visual evidence of motion events at this location, but this is not yet identified in the landslide database, although landsliding was verified in a local newspaper report. The geology at this location comprises till over Carboniferous limestone.

\subsection{Belfast City}

The greater Belfast area can be divided into low ground of the Lagan Valley which runs south-west, the northern escarpment of the Antrim Plateau and the low hills to the south-east spreading into county Down. The low lying Lagan area is dissected by the River Lagan meandering south west in an 
area underlain by Triassic Sandstone Formation and overlain by superficial raised tidal flat deposits (Figure 3 and Table 6).

The northern part is dominated by the MMG and ALG rising up to the southern edge of the Antrim Plateau. To the south east there is a series of Permian mudstones and sandstones and Ordovician greywacke. Bedrock is covered by glaciofluvial sand, gravel and deposits. A number of Paleogene basalt dykes cut the strata most notably in its northern extent.

Table 6. Reference summary geology for the Belfast area.

\begin{tabular}{cccc}
\hline Age & Group/Formation & Acronym & Lithology \\
\hline Quaternary & Till & & Basalt \\
Palaeocene & Lower Basalt Formation & LBF & Chalk \\
Cretaceous & Ulster White Limestone Formation & UWLF & Grey mudstone with thin limestone beds \\
Lower Jurassic & Waterloo Mudstone Formation & WMF & Dark grey mudstone \\
Triassic & Penarth Group & PNG & Red and green mudstone and marl with \\
Triassic & Mercia Mudstone Group & MMG & thick salt bands \\
Triassic & Sherwood Sandstone Group & SSG & Red sandstone \\
Permian & Connswater Marl Formation & CONN & ENLE \\
Permian & Enler Group & ENLE & Sandstone and subordinate breccia \\
Ordovician & Leadhills Supergroup & LHG & Wacke and Mudstone \\
\hline
\end{tabular}

During the period 1992 to 2000 Belfast ground levels appeared to have been generally stable. However, reflectors around the perimeter of the Belfast Lough (in particular on its eastern and southern sides) fall within the class defined by the -1.50 to $-2.99 \mathrm{~mm} /$ year velocity range (Figure 16a). The time series at $(334,813 ; 377,546)$ (Figure $16 \mathrm{~b}$ ) with an annual ground velocity of $-3.1 \mathrm{~mm} /$ year indicated that in some areas this is attributable to consolidation of freshly reclaimed ground.
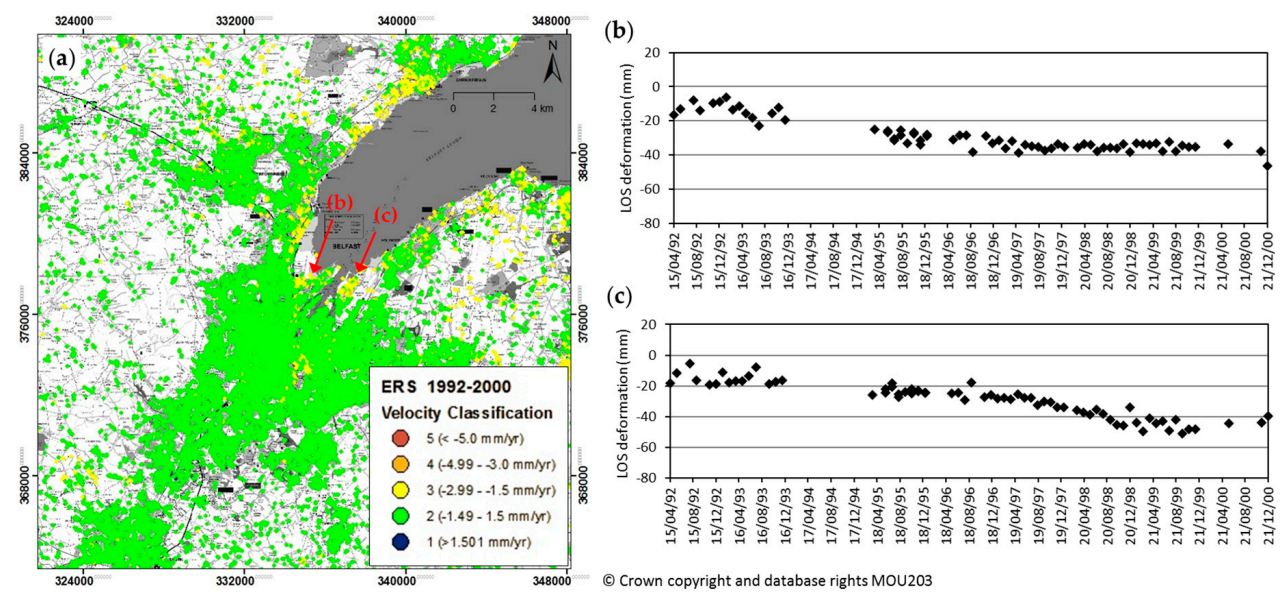

(c)

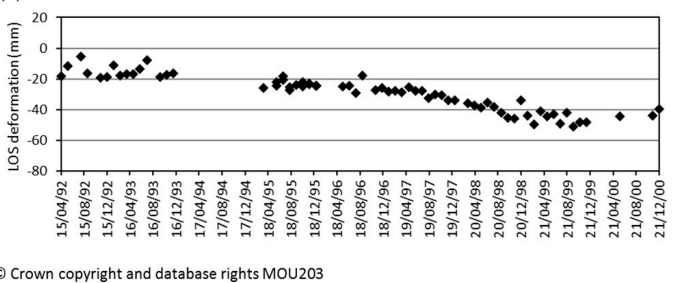

Figure 16. (a) Observed ground deformation, (b,c) time series for 1992-2000 in Belfast. Reproduced from Land and Property Services data with the permission of the Controller of Her Majesty's Stationery Office, (c) Crown copyright and database rights MOU203.

Similarly, other areas close to the harbour at $(337,212 ; 377,143)$ and $(337,187 ; 377,069)$ (Figure 16c) were subject to average velocities of -3.3 and $-3.8 \mathrm{~mm}$ /year respectively over the period 1992-2000. It is well known in the specialist InSAR literature (e.g., [21,22]) that land subsidence movements of such type are surface descriptors of interactions between local geology and urban development.

\section{Conclusions and Future Work}

By analysing InSAR results for 1992-2000, together with the landslide and mine databases, geological data and historical records, this study contributes to the understanding of the geological 
and potential anthropogenic causes (e.g., rainfall, engineering works, mining-related drivers, lowering of the water table through water abstraction) of the observed motion in Northern Ireland. Moreover, it allows potential future hazards to the geotechnical infrastructure to be identified, by providing time series data that extend the traditional monitoring period and given an indication of how events built.

Collaborative engagement with stakeholders has been very beneficial in accessing monitoring data for ground truthing the InSAR results. The benefit for the stakeholders from such an approach is multi-facetted. TransportNI anticipated that the use of InSAR data would have provided an enhanced capability to monitor and assess landslide hazards across the whole 21,000 km of road network, and helped them to form their strategies for monitoring their geotechnical assets to feed into the existing GIS based risk assessment methods for their infrastructure assets. The site at Straidkilly was only one of many sections along the A2 coast road that is unstable and InSAR has provided an improved insight into the behaviour of geohazards that impact on the road, for instance at Garron Point, therefore providing information towards their maintenance strategies and more cost-effective and better targeted maintenance.

TransportNI also were committed to having a better understanding of the mechanisms of failure on the slow moving failures on the Throne Bend in Belfast. Unfortunately, the InSAR results provided an extremely low density of targets in this area due to its rural land cover, not allowing an enhanced understanding of the magnitude of ground movement to be achieved. In addition to similar benefits and impacts to TransportNI, Northern Ireland Railways aimed to correlate the slope instability against rainfall data on the Belfast-Bangor rail line, and to reduce the requirement to have staff on active rail tracks inspecting geohazards. This narrow, heavily vegetated line generated a higher density of SBAS results than might have been anticipated showing moderate rates of movement, zoned around the central area of Bangor.

The Department for the Economy anticipated that the study would have validated new methods of monitoring and provide baseline data of ground motion to form the basis of future strategic decisions in regards to geohazards. This would enable a greater capability to assess and communicate the risk posed by ground subsidence and support the planning process in determining zones of movement with greater accuracy. The use of InSAR at sites in Carrickfergus provided additional knowledge of subsidence rates in the eight years preceding the collapse of August 2001 (i.e., 1992-2000). Integrated at local scale with a SUAV surveying carried out in 2016, it also highlighted indicators of new surface features in the area of the 2001 collapse, thus demonstrating the need for surveying technologies at higher resolution when dealing with localised deformation such as that occurring at Maiden Mount salt mine.

Our close collaboration with the stakeholders in this work has proved the need of an effective knowledge transfer, from remote sensing experts and scientists to practitioners and infrastructure managers. Future work in the project will be focused on enhancing the stakeholders' perception of the full potential of InSAR data as well as their synergy with localised investigations of instability indicators through generation and inspection of VHR surface models.

Analysis of more recent ground deformation data derived from the processing of ENVISAT time series will be also carried out, and geostatistical analysis of the results to identify correlation, anomalies and trend deviations occurring along the transport networks and mining sites to highlight any sectors needing particular attention and maintenance for the stakeholders to focus resources.

Since satellite SAR imagery is now available almost globally and freely (for instance from the Sentinel-1 constellation), potentially any geotechnical infrastructure network and respective managers could benefit from improved network-wide monitoring and a better long-term understanding of ground behaviour from InSAR techniques.

Not only transport infrastructure but also utility networks (such as supplying water, electricity or gas) are required to monitor ground stability and this is currently particularly difficult where utilities cross remote areas. In this context, InSAR could also be used for terrain evaluation, route planning and regular monitoring for utility and transport corridors. Future efforts in the project will 
be devoted to extending the knowledge transfer to a wider range of stakeholders to increase the reach of these techniques.

Acknowledgments: This work is funded to the authors by the Natural Environment Research Council (NERC) under the Environmental Risks to Infrastructure Innovation Programme (ERIIP). NERC grants: NE/N013018/1 (Lead PI: D. Hughes) and NE/N013042/1 (PI: F. Cigna): InSAR for geotechnical infrastructure: enabling stakeholders to remotely assess environmental risk and resilience (February 2016-July 2017). ERS-1/2 and ENVISAT satellite data were provided by the European Space Agency (ESA) under grant id.32627. The authors would like to thank DroneLab (https:/ / www.dronelab.io/) for hosting the SUAV-derived ortho-photographs at no cost. F. Cigna, V. Banks, A. Donald and K. Parker publish with the permission of the Executive Director of the British Geological Survey-NERC. Land and Property Services data are reproduced with the permission of the Controller of Her Majesty's Stationery Office, (c) Crown copyright and database rights MOU203.

Author Contributions: F.C., V.B., A.D., K.P., D.H., J.M, S.D. and C.G. designed the project; F.C. designed the InSAR analysis and carried out the ERS-1/2 image processing; C.G. led and carried out the SUAV campaign, and created 2D and 3D models; V.B., A.D., K.P., D.H., J.M. and S.D. analysed the InSAR data for the areas of interest; K.P. collated the mining monitoring data; F.C. wrote the paper with equal contributions from V.B., A.D., K.P., D.H., J.M. S.D. and C.G.

Conflicts of Interest: The authors declare no conflict of interest. The funding sponsors had no role in the design of the study; in the collection, analyses, or interpretation of data; in the writing of the manuscript, and in the decision to publish the results.

\section{Appendix A}

A low resolution version of our SUAV-derived digital surface model (DSM) of the Maiden Mount salt mine collapse at Carrickfergus, UK, based on the 2016 campaign is freely available for 3D displaying and download at SketchFab: https://skfb.ly/QQMG (Figure A1).

Full resolution web-views of the VHR ortho-photographs are also available for displaying at DroneLab: http://go.qub.ac.uk/SMORTHO16 and http://go.qub.ac.uk/SMORTHO17 (Figure A2).

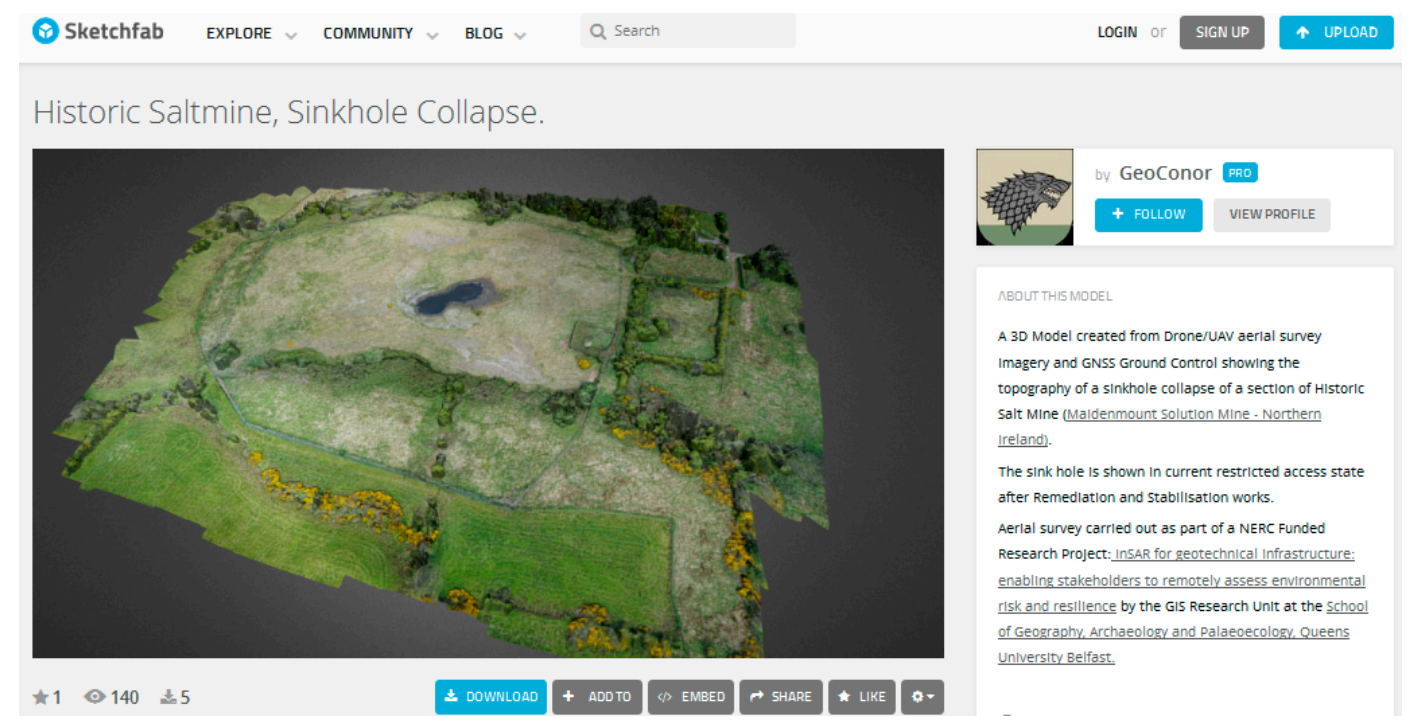

Figure A1. SUAV-derived DSM of the Maiden Mount salt mine collapse at Carrickfergus, UK, available for 3D displaying and download via SketchFab. 

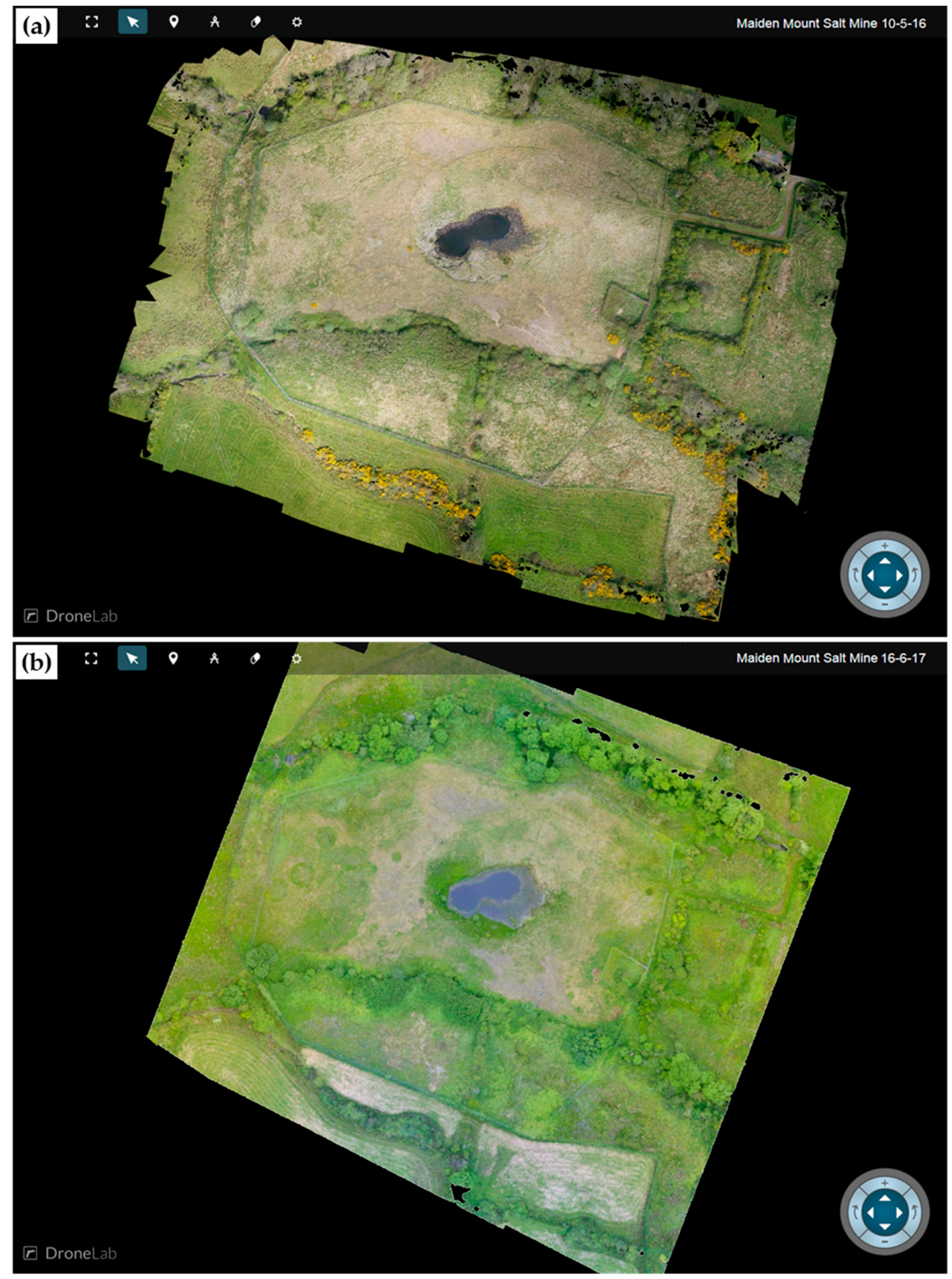

Figure A2. SUAV-derived VHR ortho-photographs of the Maiden Mount salt mine collapse at Carrickfergus, UK, based on the (a) 2016 and (b) 2017 campaigns and made available via DroneLab.

\section{References}

1. Mitchell, W.I. The Geology of Northern Ireland: Our Natural Foundation; Geological Survey of Northern Ireland: Belfast, UK, 2004; p. 318.

2. Rosen, P.A.; Hensley, S.; Joughin, I.R.; Fuk, K.L.; Madsen, S.N.; Rodriguez, E.; Goldstein, R.M. Synthetic aperture radar interferometry. Proc. IEEE 2000, 88, 333-382. [CrossRef]

3. Colesanti, C.; Wasowski, J. Investigating landslides with space-borne synthetic aperture radar (SAR) interferometry. Eng. Geol. 2006, 88, 173-199. [CrossRef]

4. Cigna, F.; Bianchini, S.; Casagli, N. How to assess landslide activity and intensity with Persistent Scatterer Interferometry (PSI): The PSI-based matrix approach. Landslides 2013, 10, 267-283. [CrossRef] 
5. Herrera, G.; Gutiérrez, F.; García-Davalillo, J.C.; Guerrero, J.; Notti, D.; Galve, J.P.; Fernández-Merodo, J.A.; Cooksley, G. Multi-sensor advanced DInSAR monitoring of very slow landslides: The Tena Valley case study (Central Spanish Pyrenees). Remote Sens. Environ. 2013, 128, 31-43. [CrossRef]

6. Galloway, D.L.; Hudnut, K.W.; Ingebritsen, S.E.; Phillips, S.P.; Peltzer, G.; Rogez, F.; Rosen, P.A. Detection of aquifer system compaction and land subsidence using interferometric synthetic aperture radar, Antelope Valley, Mojave Desert, California. Water Resour. Res. 1998, 34, 2573-2585. [CrossRef]

7. Bell, J.W.; Amelung, F.; Ferretti, A.; Bianchi, M.; Novali, F. Permanent scatterer InSAR reveals seasonal and long-term aquifer-system response to groundwater pumping and artificial recharge. Water Resour. Res. 2008, 44, W02407. [CrossRef]

8. Cigna, F.; Osmanoğlu, B.; Cabral-Cano, E.; Dixon, T.H.; Ávila-Olivera, J.A.; Gardũno-Monroy, V.H.; DeMets, C.; Wdowinski, S. Monitoring land subsidence and its induced geological hazard with Synthetic Aperture Radar Interferometry: A case study in Morelia, Mexico. Remote Sens. Environ. 2012, 117, 146-161. [CrossRef]

9. Bell, A.D.F.; McKinley, J.M.; Hughes, D.A.B.; Hendry, M.; Macciotta, R. Spatial and temporal analyses using Terrestrial LiDAR for monitoring of landslides to determine key slope instability thresholds: Examples from Northern Ireland and Canada. In Proceedings of the 6th Canadian GeoHazards Conference-GeoHazards 6, Kingston, ON, Canada, 15-18 June 2014. [CrossRef]

10. Berardino, P.; Fornaro, G.; Lanari, R.; Sansosti, E. A new algorithm for surface deformation monitoring based on small baseline differential interferograms. IEEE Trans. Geosci. Remote 2002, 40, 2375-2383. [CrossRef]

11. Cook, K.L. An evaluation of the effectiveness of low-cost UAVs and structure from motion for geomorphic change detection. Geomorphology 2017, 278, 195-208. [CrossRef]

12. Lindner, G.; Schraml, K.; Mansberger, R.; Hübl, J. UAV monitoring and documentation of a large landslide. Appl. Geomat. 2016, 8, 1-11. [CrossRef]

13. Niethammer, U.; James, M.R.; Rothmund, S.; Travelletti, J.; Joswig, M. UAV-based remote sensing of the Super-Sauze landslide: Evaluation and results. Eng. Geol. 2012, 128, 2-11. [CrossRef]

14. Fernández, T.; Pérez, J.L.; Cardenal, J.; Gómez, J.M.; Colomo, C.; Delgado, J. Analysis of Landslide Evolution Affecting Olive Groves Using UAV and Photogrammetric Techniques. Remote Sens. 2016, 8, 837. [CrossRef]

15. Chen, J.; Li, K.; Chang, K.J.; Sofia, G.; Tarolli, P. Open-pit mining geomorphic feature characterisation. Int. J. Appl. Earth Obs. 2015, 42, 76-86. [CrossRef]

16. Smith, M.W.; Carrivick, J.L.; Quincey, D.J. Structure from motion photogrammetry in physical geography. Prog. Phys. Geogr. 2015, 40, 247-275. [CrossRef]

17. Ely, J.; Graham, C.; Barr, I.; Rea, B.; Spagnolo, M.; Evans, J. Using SUAV acquired photography and structure from motion techniques for studying glacier landforms: Application to the glacial flutes at Isfallsglaciären. Earth Surf. Process. Landf. 2016, 42, 877-888. [CrossRef]

18. Ge, D.; Wang, Y.; Zhang, L.; Xia, Y.; Wang, Y.; Guo, X. Using Permanent Scatterer InSAR to monitor land subsidence along high speed railway-The first experiment in China. In Proceedings of the Workshop Fringe 2009 ESA SP-677, Frascati, Italy, 30 November-4 December 2009.

19. Skempton, A.W.; Hutchinson, J.N. Slope Problems on the North-East Side of Cave Hill; A Report for the Ministry of Development; Imperial College London: London, UK, 1970.

20. Cigna, F.; Bateson, L.; Jordan, C.J.; Dashwood, C. Simulating SAR geometric distortions and predicting Persistent Scatterer densities for ERS-1/2 and ENVISAT C-band SAR and InSAR applications: Nationwide feasibility assessment to monitor the landmass of Great Britain with SAR imagery. Remote Sens. Env. 2014, 152, 441-466. [CrossRef]

21. Pratesi, F.; Tapete, D.; Del Ventisette, C.; Moretti, S. Mapping interactions between geology, subsurface resource exploitation and urban development in transforming cities using InSAR Persistent Scatterers: Two decades of change in Florence, Italy. Appl. Geogr. 2016, 77, 20-37. [CrossRef]

22. Cigna, F.; Jordan, H.; Bateson, L.; McCormack, H.; Roberts, C. Natural and anthropogenic geohazards in greater London observed from geological and ERS-1/2 and ENVISAT persistent scatterers land subsidence data: Results from the EC FP7-SPACE PanGeo Project. Pure Appl. Geophys. 2015, 172, 2965-2995. [CrossRef]

(C) 2017 by the authors. Licensee MDPI, Basel, Switzerland. This article is an open access article distributed under the terms and conditions of the Creative Commons Attribution (CC BY) license (http:/ / creativecommons.org/licenses/by/4.0/). 